\title{
Open versus endoscopic carpal tunnel release: a systematic review and meta- analysis of randomized controlled trials
}

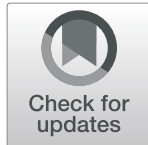

Yueying Li', Wenqi Luo², Guangzhi Wu', Shusen Cui', Zhan Zhang ${ }^{1 *}$ and Xiaosong Gu ${ }^{1 *}$ (D)

\begin{abstract}
Background: Endoscopic carpal tunnel release (ECTR) and open carpal tunnel release (OCTR) both have advantages and disadvantages for the treatment of carpal tunnel syndrome (CTS). We compared the effectiveness and safety of ECTR and OCTR based on evidence from a high-level randomized controlled trial.

Methods: We comprehensively searched PubMed, EMBASE, Cochrane Library, Web of Science, and Medline to identify relevant articles published until August 2019. Data regarding operative time, grip strength, Boston Carpal Tunnel Questionnaire scores, digital sensation, patient satisfaction, key pinch strength, return to work time, and complications were extracted and compared. All mean differences (MD) and odds ratios (OR) were expressed as ECTR relative to OCTR.
\end{abstract}

Results: Our meta-analysis contained twenty-eight studies. ECTR was associated with significantly higher satisfaction rates (MD, 3.13; 95\% confidence interval $[C I], 1.43$ to $4.82 ; P=0.0003)$, greater key pinch strengths $(M D$, $0.79 \mathrm{~kg} ; 95 \% \mathrm{Cl}, 0.27$ to $1.32 ; P=0.003)$, earlier return to work times $(\mathrm{MD},-7.25$ days; $95 \% \mathrm{Cl},-14.31$ to $-0.19 ; P=$ $0.04)$, higher transient nerve injury rates $(\mathrm{OR}, 4.87 ; 95 \% \mathrm{Cl}, 1.37$ to $17.25 ; P=0.01)$, and a lower incidence of scarrelated complications $(\mathrm{OR}, 0.20 ; 95 \% \mathrm{Cl}, 0.07$ to $0.59 ; P=0.004)$. The permanent nerve injury showed no significant differences between the two methods $(\mathrm{OR}, 1.93 ; 95 \% \mathrm{Cl}, 0.58$ to $6.40 ; P=0.28)$.

Conclusions: Overall, evidence from randomized controlled trials indicates that ECTR results in better recovery of daily life functions compared to OCTR, as revealed by higher satisfaction rates, greater key pinch strengths, earlier return to work times, and fewer scar-related complications. Our findings suggest that patients with CTS can be effectively managed with ECTR.

Keywords: Carpal tunnel syndrome, Complications, Endoscopic carpal tunnel release, Meta-analysis, Open carpal tunnel release, Randomized controlled trial

\footnotetext{
*Correspondence: 2334461384@qq.com; 2622489738@qq.com

Yueying $\mathrm{Li}$ is the first author

${ }^{1}$ Department of Hand Surgery, China-Japan Union Hospital of Jilin University,

No. 126 Xiantai Street, Changchun, Jilin 130033, P.R. China

Full list of author information is available at the end of the article
}

\section{$\triangle B M C$}

(c) The Author(s). 2020 Open Access This article is licensed under a Creative Commons Attribution 4.0 International License, which permits use, sharing, adaptation, distribution and reproduction in any medium or format, as long as you give appropriate credit to the original author(s) and the source, provide a link to the Creative Commons licence, and indicate if changes were made. The images or other third party material in this article are included in the article's Creative Commons licence, unless indicated otherwise in a credit line to the material. If material is not included in the article's Creative Commons licence and your intended use is not permitted by statutory regulation or exceeds the permitted use, you will need to obtain permission directly from the copyright holder. To view a copy of this licence, visit http://creativecommons.org/licenses/by/4.0/ The Creative Commons Public Domain Dedication waiver (http://creativecommons.org/publicdomain/zero/1.0/) applies to the data made available in this article, unless otherwise stated in a credit line to the data. 


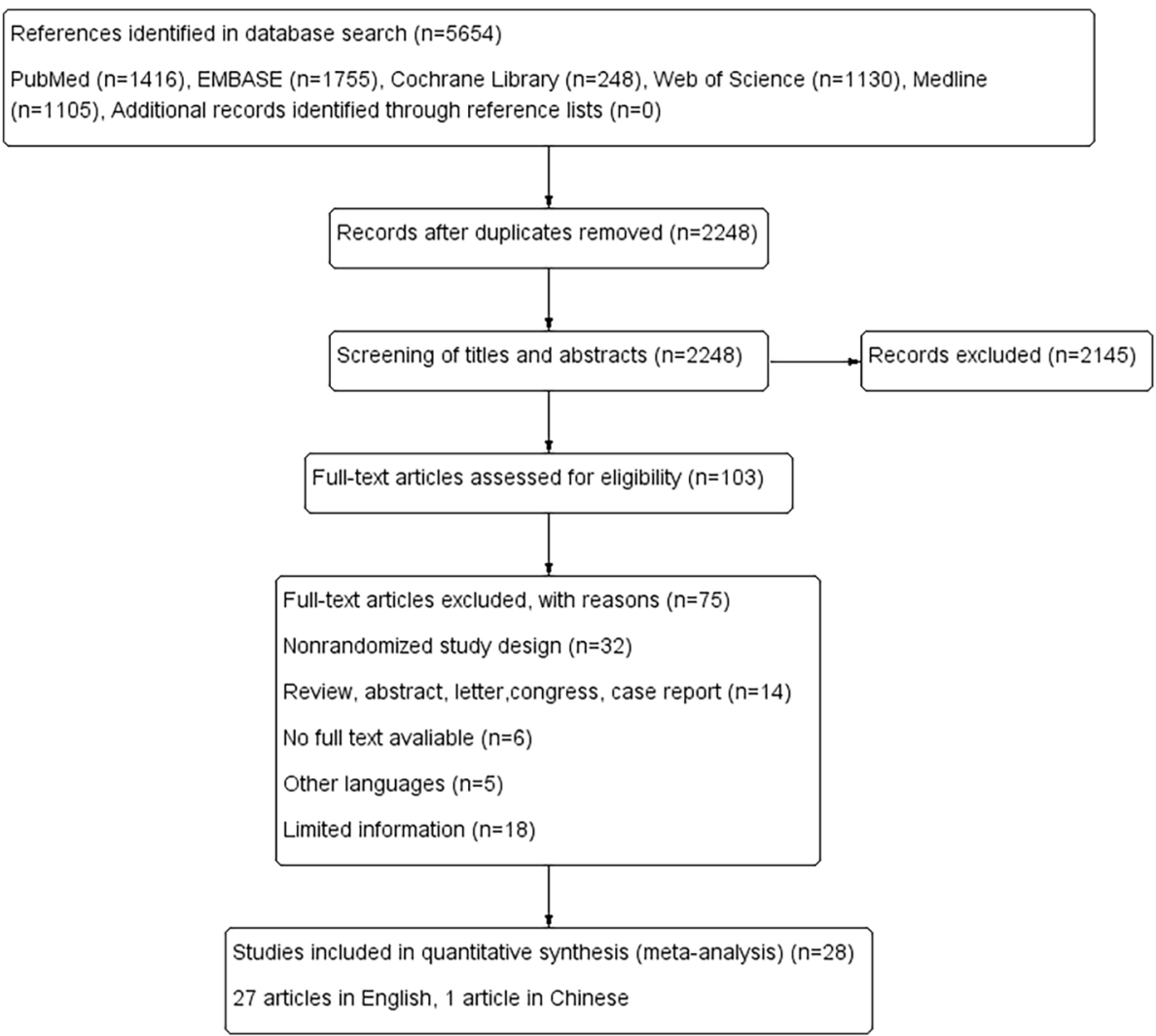

Fig. 1 Flow diagram of the study selection process

\section{Background}

Carpal tunnel syndrome (CTS), known as compressive median mononeuropathy at the wrist, causes tingling, numbness, and pain along the radial side of the hand [1]. The reported estimates for its annual prevalence range from 0.18 to $5 \%$ [2-5]. CTS can be treated surgically or non-surgically; however, non-surgical management that involves wrist splinting, corticosteroid injections, and physiotherapy, is preferred over surgical management for mild and moderate CTS [6, 7]. Surgical treatments for CTS, including the open carpal tunnel release (OCTR) and endoscopic carpal tunnel release (ECTR) approach, are generally reserved for patients with severe symptoms or those who experienced conservative treatment failure $[8,9]$.

OCTR is a well-established surgical treatment for CTS [10]. However, it is associated with potential complications such as persistent weakness, pillar pain, formation of hypertrophic scars in the incisions that cross the wrist, scar tenderness, slow recovery, and a higher incidence of persistent pain [11]. In an attempt to avoid these complications, Chow [12] and Okutsu et al. [13] were the first to report the use of ECTR for the treatment of CTS in the English literature in 1989. This method allows for smaller skin incisions and better esthetic results than OCTR $[1,14,15]$. Nevertheless, ECTR is technically difficult, time consuming, and associated with incomplete transverse carpal ligament release and neurovascular injury [16-20]. Several meta-analyses have compared various measures of effectiveness and safety between ECTR and OCTR [15, 21-23]. However, these investigations failed to separate subgroups according to different follow-up times and utilized limited evaluations of patient outcomes; therefore, it is not clear which approach is associated with better clinical results $[24,25]$.

Therefore, we carried out a meta-analysis to compare the safety and availability between ECTR and OCTR according to randomized controlled trial (RCT) evidence. Specifically, we sought to determine if ECTR was superior to OCTR in terms of patient satisfaction, functional recovery, and complications.

\section{Methods}

\section{Literature search}

The Preferred Reporting Items for Systematic Reviews and Meta-Analyses (PRISMA) trial flow shows the inclusion process for the RCTs in the meta-analysis [26]. Two authors respectively used the following computerized bibliographic databases: PubMed, EMBASE, 
Table 1 Study characteristics of the randomized controlled trials included in the meta-analysis

\begin{tabular}{|c|c|c|c|c|c|}
\hline Author & Year & Region & Groups, sample sizes, and techniques & Follow-up interval & Outcomes \\
\hline Agee et al. [28] & 1992 & US & $\begin{array}{l}\text { OCTR }(n=65) \text { : conventional release } \\
\text { ECTR }(n=82) \text { : one-portal }(2 \mathrm{~cm})\end{array}$ & $\begin{array}{l}1,2,3,6,9,13,26 \\
\text { week(s) }\end{array}$ & $\begin{array}{l}\text { Return of hand use for ADL, time to RTW, } \\
\text { grip strength, pinch strength, lateral/key } \\
\text { and pulp strength, SW monofilament test, } \\
\text { Phalen's wrist flexion test, Tinel's test, scar } \\
\text { tenderness, radial and ulnar pillar } \\
\text { tenderness, record of medication use, } \\
\text { complications }\end{array}$ \\
\hline
\end{tabular}

\begin{tabular}{|c|c|c|c|c|}
\hline Atroshi et al. [9] & 2006 & Sweden & $\begin{array}{l}\operatorname{OCTR}(n=65): 4 \mathrm{~cm} \\
\text { ECTR }(n=63): \text { two-portal }(1 \mathrm{~cm})\end{array}$ & $\begin{array}{l}3,6 \text { weeks; } \\
3,12 \text { months }\end{array}$ \\
\hline Atroshi et al. [29] & 2009 & Sweden & $\begin{array}{l}\operatorname{OCTR}(n=63): 4 \mathrm{~cm} \\
\text { ECTR }(n=63): \text { two-portal }(1 \mathrm{~cm})\end{array}$ & 1, 5 year(s) \\
\hline Atroshi et al. [25] & 2015 & Sweden & $\begin{array}{l}\operatorname{OCTR}(n=61): 4 \mathrm{~cm} \\
\operatorname{ECTR}(n=63): \text { two-portal }(1 \mathrm{~cm})\end{array}$ & $1,11-16$ year \\
\hline Aslani et al. [30] & 2012 & Iran & $\begin{array}{l}\text { OCTR }(n=36) \text { : conventional release } \\
\text { OCTR }(n=28) \text { : mini-incision } \\
\text { ECTR }(n=32) \text { : two-portal (length NR) }\end{array}$ & $\begin{array}{l}4 \text { weeks; } \\
4 \text { months }\end{array}$ \\
\hline
\end{tabular}

Brown et al. [31] 1993 US

Dumontier et al. [32] 1995 France

Ejiri et al. [33] 2012 Japan

Erdmann [34] 1994 UK

Ferdinand and

2002 UK

MacLean [35]

Gümüştaş et al. [36] 2015 Turkey

Jacobson and

Rahme [38]

Kang et al. [39]

Larsen et al. [40]
1996 Sweden

2013 South Korea

2013 Denmark
$\operatorname{OCTR}(n=82)$ : conventional release $\operatorname{ECTR}(n=78)$ : two-portal $(2 \mathrm{~cm})$
$3,6,12$ weeks

2 weeks;

1, 3, 6 month(s)

$\operatorname{ECTR}(n=56)$ : two-portal (Chow [12])

$\operatorname{OCTR}(n=50): 3 \mathrm{~cm}$ vertical incision ECTR $(n=50)$ : one-portal (Okutsu et al. [13])

OCTR $(n=52)$ : NR (short length) $\operatorname{ECTR}(n=53)$ : two-portal (Chow [12])

$\operatorname{OCTR}(n=25): \mathrm{NR}$ $\operatorname{ECTR}(n=25)$ : one-portal

OCTR $(n=20)$ : NR (Taleisnik [37]) ECTR $(n=21)$ : two-portal (Chow [12])

OCTR $(n=16)$ : conventional release ECTR $(n=16)$ : two-portal (Chow [12])

$\operatorname{OCTR}(n=52)$ : mini-incision $(1.5 \mathrm{~cm})$ $\operatorname{ECTR}(n=52)$ : one-portal (Agee et al. [28])

OCTR $(n=30)$ : classic incision, $7 \mathrm{~cm}$ OCTR $(n=30)$ : short incision, $3 \mathrm{~cm}$ ECTR $(n=30)$ : one-portal (Menon [41])
1, 3 month(s)

1, 2 week(s); 1, 3, 6 month(s); 1 year

6, 12, 26 weeks: 13 months

6 months

$2,6,24$ weeks

3 months

$1,2,3,6,12,24$ week(s)

Pain, time to RTW, BCTQ-S, BCTQ-F, SF-12, sensation, grip strength, key pinch strength, $\mathrm{DL}$, quality of life, SW monofilament test, 2PD test, complications

Operative time, satisfaction rating, symptom relief, BCTQ-S, BCTQ-F, pain score, complications

BCTQ-S, BCTQ-F, pain score, numbness and tingling, satisfaction score, quick DASH, pain scale, complications

Numbness, nocturnal pain, wrist pain, weakness and stiffness, Tinel's test, Phalen's wrist flexion test, EMG, NCV, strength to grasp, time to RTW and ADL, satisfaction rating, operative time, complications

2PD test, SW monofilament test, APB strength, thenar atrophy, grip strength, key pinch strength, pain, numbness, paresthesia, weakness, Tinel's test, Phalen's wrist flexion test, interstitial carpal tunnel pressure, satisfaction rating, time to RTW, rate of $\mathrm{ADL}$ impairment, $\mathrm{ADL}$ score, operative time, hospital cost, complications

Paresthesia, pain, time to RTW, grip strength, finger mobility, complications

Paresthesia, nighttime pain, impairment of ADL, APB-DL, SW monofilament test, 2PD test, grip strength, pinch strength, key pinch strength, complications

Grip and pinch strength, time to normal grip strength, time to normal pinch strength, time to RTW, ADL, time to relief of symptoms, median nerve motor and sensory DL, VAS pain score, complications

VAS scores (numbness, pain, and paresthesia), $A D L$, return to full activities, time to RTW, thenar muscle strength, lateral pinch strength, grip strength, wrist and finger movement, 2PD test, Jebson score, operative time, satisfaction rating, complications

BCTQ-S, BCTQ-F, median nerve motor DL, CMAP, SCV, sensory nerve action potential, complications

Symptom relief, total number of analgesics, 2PD test, time to RTW, nerve conduction test, complications

BCTQ-S, BCTQ-F, DASH, complications

VAS (pain), grip strength, range of motion, pillar pain, VAS (paresthesia), time to RTW, complications 
Table 1 Study characteristics of the randomized controlled trials included in the meta-analysis (Continued)

\begin{tabular}{|c|c|c|c|c|c|}
\hline Author & Year & Region & Groups, sample sizes, and techniques & Follow-up interval & Outcomes \\
\hline $\begin{array}{l}\text { Macdermid et al. } \\
\text { [42] }\end{array}$ & 2003 & Canada & $\begin{array}{l}\text { OCTR }(n=32) \text { : conventional release } \\
\text { ECTR }(n=91) \text { : two-portal (Chow [12]) }\end{array}$ & 1, 6, 12 week(s) & $\begin{array}{l}\text { Time to RTW, McGill pain questionnaire, } \\
\text { key pinch strength, tripod pinch strength, } \\
\text { grip strength, symptom severity score } \\
\text { (Likert score), sensory threshold, self-report } \\
\text { scale, SF-36, complications }\end{array}$ \\
\hline
\end{tabular}

Mackenzie et al. [43] 2000 US

Martínez et al. [24] 2019 Spain

Michelotti et al. [44] 2014 US

Michelotti et al. [45] 2018 US

2017 South Korea

Rab et al. [47]

2006 Austria

Saw et al. [48] 2003 UK

Sennwald and

Benedetti [49]

Tian et al. [50]

2007 China

Trumble et al. [51] 2002 US

Wong et al. [52]

2003 Hong

Kong

$\operatorname{OCTR}(n=14): 2.5 \mathrm{~cm}$ palmar incision

ECTR $(n=22)$ : one-portal (Agee et al. [28])

OCTR $(n=52): 1 \mathrm{~cm}$ mini-incision 1 week $\operatorname{ECTR}(n=35)$ : one-portal (Menon [41]) 1, 6, 12 month(s)

OCTR $(n=25): 3 \mathrm{~cm}$ palmar incision ECTR $(n=25)$ : one-portal (Agee et al. [28], $1.5 \mathrm{~cm}$ )

OCTR $(n=30): 3 \mathrm{~cm}$ palmar incision ECTR $(n=30)$ : one-portal (Agee et al. [28], 1.5 to $2 \mathrm{~cm}$ )

OCTR $(n=32)$ : mini-incision $(1.5 \mathrm{~cm})$ $\mathrm{ECTR}(n=35)$ : one-portal (Agee et al. [28], $1.5 \mathrm{~cm}$ )

$\operatorname{OCTR}(n=10)$ : two mini-incisions $\operatorname{ECTR}(n=10)$ : two-portal (Chow [12])

$2,4,6,12$ weeks; 6 12 months

$\operatorname{OCTR}(n=42): 2 \mathrm{~cm}$ palmar incision ECTR $(n=43)$ : one-portal (Agee et al. [28])

1995 Switzerland OCTR $(n=22)$ : Sennwald incision ECTR $(n=25)$ : one-portal (Agee et al. [28], 2-3 cm)

$\operatorname{OCTR}(n=36)$ : S-shaped incision ECTR $(n=34)$ : one-portal (Okutsu et al. [13], $1 \mathrm{~cm})$

OCTR $(n=95)$ : palmar incision $(3 \sim 4$ $\mathrm{cm})$

ECTR ( $n=97)$ : one-portal (Agee et al. [28], $1 \mathrm{~cm})$

$\operatorname{OCTR}(n=30)$ : mini-incision

ECTR $(n=30)$ : two-portal (Chow [12])

$2,4,8,16$ weeks; 6

$\operatorname{OCTR}(n=72)$ : double small incision OCTR $(n=65)$ : standard incision (5-7 $\mathrm{cm})$

ECTR ( $n=69)$ : two-portal (Chow [12])

Zhao et al. [54]
12 months

$2,4,8,12,26,52$ weeks

3 years
OCTR $(n=21)$ : S-shaped incision 2 years ECTR $(n=26)$ : one-portal (Okutsu et al. [13], $1 \mathrm{~cm})$
Grip strength, pinch strength, BCTQ-S, BCTQ-F, complications

Grip strength, pinch strength, VAS pain score, satisfaction questionnaire, complications

2PD test, SW monofilament test, thenar strength, grip strength, BCTQ-S, BCTQ-F, satisfaction rating, complications

VAS pain score, 2PD test, SW monofilament test, thenar strength, grip strength, BCTQ-S, BCTQ-F, satisfaction rating, complications

BCTQ-S, BCTQ-F, DASH, CSA, CSA-I, CSA-M, CSA-O, flattening ratio, complications

VAS pain score, grip strength, pinch strength, key pinch strength, ADL, BCTQ-S, BCTQ-F, 2PD, DL, NCV, complications

BCTQ-S, BCTQ-F, grip strength, VAS pain score, time to RTW, operation time, complications

Grip strength, key pinch strength, time to RTW, complications

Symptom improvement, operation time, hospital stay time, time to RTW, 2PD test, grip strength, scar tenderness, complications

BCTQ-S, BCTQ-F, 2PD test, satisfaction rating, grip strength, pinch strength (key pinch, three-jaw), hand dexterity, time to RTW, thenar atrophy, strength of APB, complications

VAS pain score, grip strength, pinch strength, 2PD test, operation time, symptom relief, incision length, complications

BCTQ-S, BCTQ-F, patient satisfaction, VAS pain score, cylindrical strength, lateral strength, pinch strength, grip strength, time to RTW, 2PD test, SW monofilament test, hospital cost, complications

EMG, operation time, hospital stay time, 2PD test, time to RTW, complications

2PD Two-point Discrimination, $A D L$ activities of daily living, $A P B$ abductor pollicis brevis, $B C T Q-F$ Boston Carpal Tunnel Questionnaire Functional Status Scale, $B C T Q-$ $S$ Boston Carpal Tunnel Questionnaire Symptom Severity Scale, CMAP compound muscle action potential, CSA cross-sectional area, CSA-I inlet at the distal wrist crease level, CSA-M the middle of the tunnel at the level of the pisiform, CSA-O the tunnel outlet at the level of the hamate hook, DASH Disability of Arm, Shoulder, and Hand Questionnaire, DL distal latency, ECTR endoscopic carpal tunnel release, EMG electromyography, NCV nerve conduction velocity, NR not reported, OCTR open carpal tunnel release, RTW return to work, SCV sensory conduction velocity, SF-12 12-Item Short Form Health Survey, SF-36 36-Item Short Form Health Survey, SW Semmes-Weinstein, UK United Kingdom, US United States, VAS Visual Analog Scale 


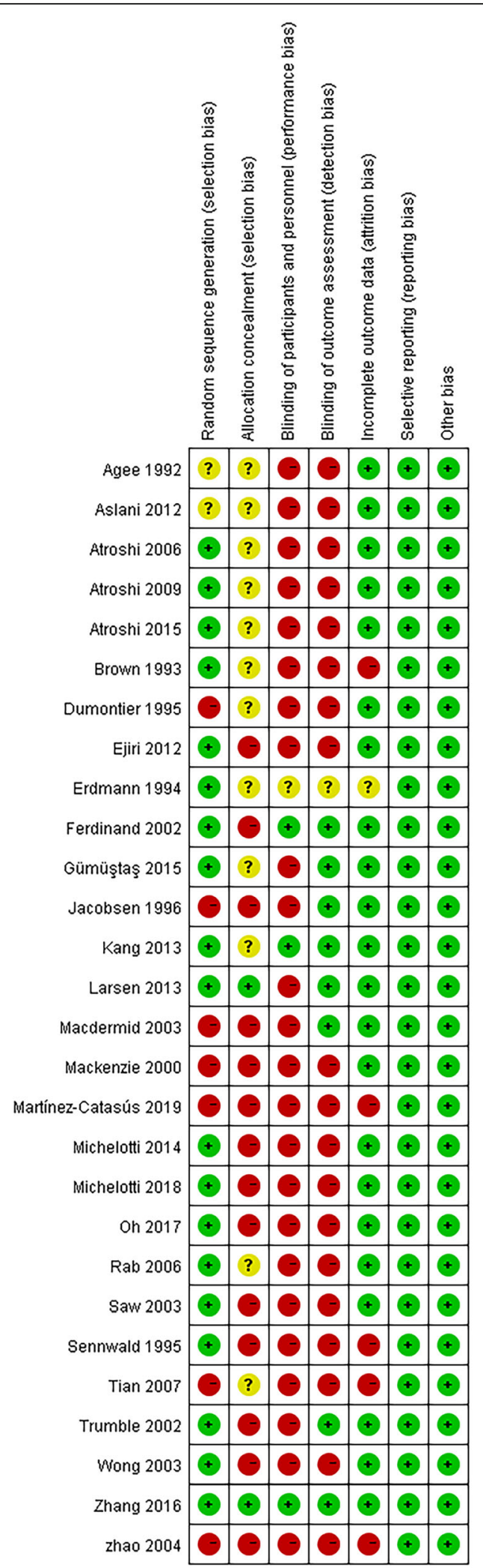

Fig. 2 Risk of bias assessment for included randomized controlled trials
Cochrane Library, Web of Science, and Medline databases to search for relevant publications. Publications from the inception of each database to August 10, 2019 were searched. The keywords used in the searches were "carpal tunnel" plus "open incision" and "carpal tunnel" plus "endoscopic." We also manually scanned the reference lists to identify other relevant studies, that were discovered using these search terms.

\section{Eligibility criteria}

A study was included if it was an RCT that compared OCTR and ECTR. The exclusion criteria were as follows: 1) descriptive or graphic outcomes with no standard deviation values, 2) studies that included modification surgery, 3) studies that did not coverage the follow-up time, 4) studies that only recorded limited qualitative findings, 5) studies published in a language other than English or Chinese, and 6) technique articles, abstracts, and nontherapeutic studies. Finally, two investigators independently reviewed all selected studies for inclusion.

\section{Data abstraction}

Two authors extracted valuable data from the included studies respectively. When data heterogeneity is present, it must be resolved by containing a third author until data heterogeneity was reached a consensus for all items.

The extracted data included publication year, region, sample capacity, intervention, follow-up interval, and outcomes in eligible studies. Plot-digitizing software (Plot Digitizer Version 2.6.4; Joseph Huwaldt and Scott Steinhorst, http://www.plot-digitizer.com-about.com/) was used to quantify the data only recorded graphically. The pooled analysis outcome parameters were as follows: operation duration; scores on several clinical indexes, including the Boston Carpal Tunnel Questionnaire Symptom Severity Scale (BCTQ-S), Boston Carpal Tunnel Questionnaire Functional Status Scale (BCTQ-F), Two-point Discrimination test, and Semmes-Weinstein monofilament test; grip strength; key pinch strength; time to return to work (RTW); patients' subjective ratings of their satisfaction with symptom improvement following CTS release based on a scale of 0 to 100 points; and postoperative complications.

\section{Validity assessment}

The level of evidence was assessed by the Grading of Recommendations Assessment, Development, and Evaluation (GRADE) guidelines [27]. At least two authors respectively evaluated the risk of bias, and disagreements were discussed until a consensus was reached. 


\begin{tabular}{|c|c|c|c|c|c|c|c|c|c|}
\hline \multirow[b]{2}{*}{ Studv or Subgroup } & \multicolumn{2}{|c|}{ ECTR } & \multicolumn{3}{|c|}{ OCTR } & \multirow[b]{2}{*}{ Total } & \multirow[b]{2}{*}{ Weight } & \multirow{2}{*}{$\begin{array}{l}\text { Mean Difference } \\
\text { N. Random. } 95 \% \mathrm{Cl}\end{array}$} & \multirow{2}{*}{$\begin{array}{l}\text { Mean Difference } \\
\text { IV. Random, } 95 \% \mathrm{Cl}\end{array}$} \\
\hline & Mean & SD & Total & Mean & SD & & & & \\
\hline zhao 2004 & 13 & 2 & 26 & 40 & 5 & 21 & $25.0 \%$ & $-27.00[-29.27,-24.73]$ & - \\
\hline Wong 2003 & 12.9 & 4.9 & 30 & 12.9 & 5.1 & 30 & $24.9 \%$ & $0.00[-2.53,2.53]$ & -1 \\
\hline Kang 2013 & 7.5 & 3.68 & 52 & 6.8 & 2.58 & 52 & $25.1 \%$ & $0.70[-0.52,1.92]$ & $=$ \\
\hline Ferdinand 2002 & 13 & 4 & 25 & 10 & 2 & 25 & $25.0 \%$ & $3.00[1.25,4.75]$ & - \\
\hline Total $(95 \% \mathrm{Cl})$ & & & 133 & & & 128 & $100.0 \%$ & $-5.81[-17.85,6.23]$ & \\
\hline \multicolumn{9}{|c|}{$\begin{array}{l}\text { Heterogeneity: } T^{2}=149.98 ; \mathrm{Chi}^{2}=513.93, \mathrm{df}=3(P<0.00001) ; I^{2}=99 \% \\
\text { Test for overall effect: } Z=0.95(P=0.34)\end{array}$} & $\begin{array}{ccccc}-20 & -10 & 0 & 10 & 20 \\
\text { Favours } & \text { ECTR } & \text { Favours } & \text { OCTR }\end{array}$ \\
\hline
\end{tabular}

\section{Statistical analysis}

Continuous data were analyzed through the inversevariance statistical and method and mean difference (MD) and 95\% confidence intervals (CIs) were reported. Dichotomous data were analyzed through the MantelHaenszel statistical method and odds ratio (OR) and 95\% CI were reported. All MD and OR values were collected and collated using the results from OCTR as the reference values. In addition, $\mathrm{X}^{2}$ and $\mathrm{I}^{2}$ tests were percentage of total variation that were used to assess statistical heterogeneity. When the $P$ value from the $X^{2}$ test was $<0.10$ or when the $\mathrm{I}^{2}$ value $>50 \%$ significant heterogeneity was indicated, the possible sources of heterogeneity were examined. Pooled result of the outcome was assessed by random-effects model; otherwise, a fixedeffects model was used. All tests were two-tailed, and $P<0.05$ were considered statistically significant. The funnel plot method and Egger's test were utilized to evaluate the publication bias. Review Manager (version 5.3; The Nordic Cochrane Centre, Cochrane Collaboration, Copenhagen, Denmark) was used to further analyze the data.

\section{Results}

\section{Studies selection and characteristics}

Figure 1 summarizes the screening process of the identified articles in the final analysis. In the aggregate 5654 articles were confirmed from PubMed $(n=1416)$,
EMBASE $(n=1755)$, Cochrane Library $(n=248)$, Web of Science $(n=1130)$, Medline $(n=1105)$, and reference lists $(n=0)$. After eliminated duplicates, 2248 articles remained. Reviews of the titles and abstracts decreased the articles to 103, finally this number reduced to 28 articles included in the meta-analysis after a more detailed review. Twenty-seven articles were published in English and one was published in Chinese. The included article characteristics are summed up in Table 1.

\section{Quality assessment}

In line with GRADE guidelines, 19 RCTs reported adequate methods for selection bias of random sequence generation. Only 8 RCTs had low risks of blinding of outcome assessment for results. The majority of RCTs $(25 / 28)$ had risk of performance bias. Incomplete outcome data was judged as low risk for 22 RCTs. All RCTs were at a low risk of reporting bias (Fig. 2).

\section{Results of meta-analysis}

There were no significant differences in the operative time (MD, $-5.81 \mathrm{~min}$; $95 \% \mathrm{CI},-17.85$ to $6.23 ; P=0.34$; $n=261$; random-effects model, $\mathrm{I}^{2}=99 \% ; \quad P<0.00001$; Fig. 3) $[35,39,52,54]$, grip strength at 3 months postsurgery (MD, $1.99 \mathrm{~kg} ; 95 \% \mathrm{CI},-0.43$ to $4.42 ; P=0.11$; $n=297$; fixed-effects model, $\mathrm{I}^{2}=0 \% ; P=0.79$; Fig. 4) $[9$, $31]$, BCTQ-S score at 1 year post-surgery (MD, 0.15; 95\% CI, -0.04 to $0.35 ; P=0.13 ; n=592$; random-effects

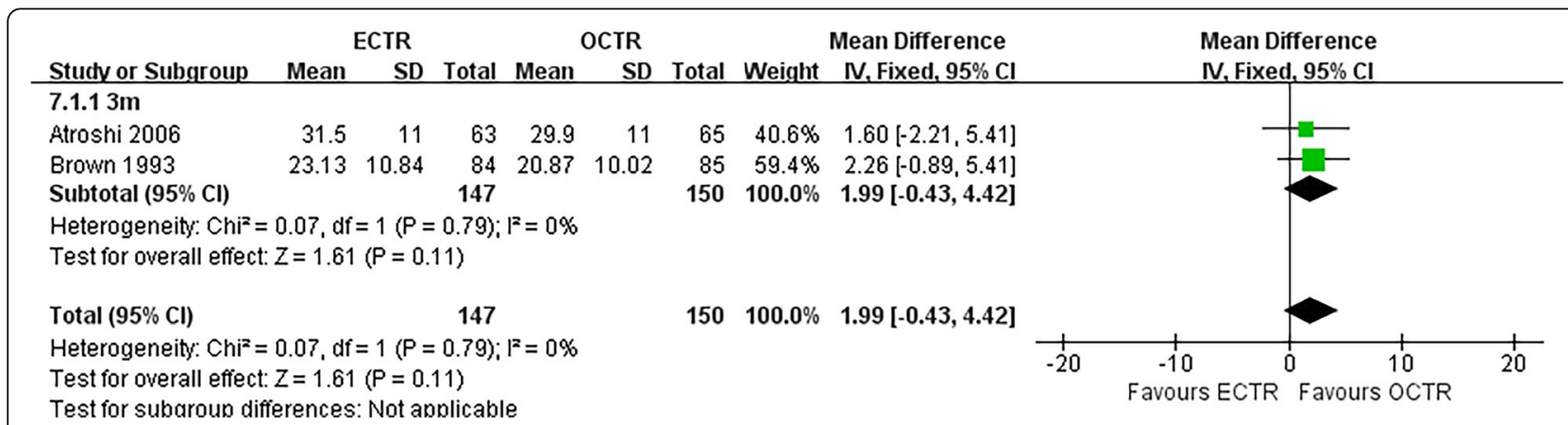

Fig. 4 Comparison of grip strength between patients who underwent ECTR and those who underwent OCTR. OCTR, open carpal tunnel release; ECTR, endoscopic carpal tunnel release; SD, standard deviation; IV, inverse-variance; Cl, confidence interval; df, degrees of freedom 


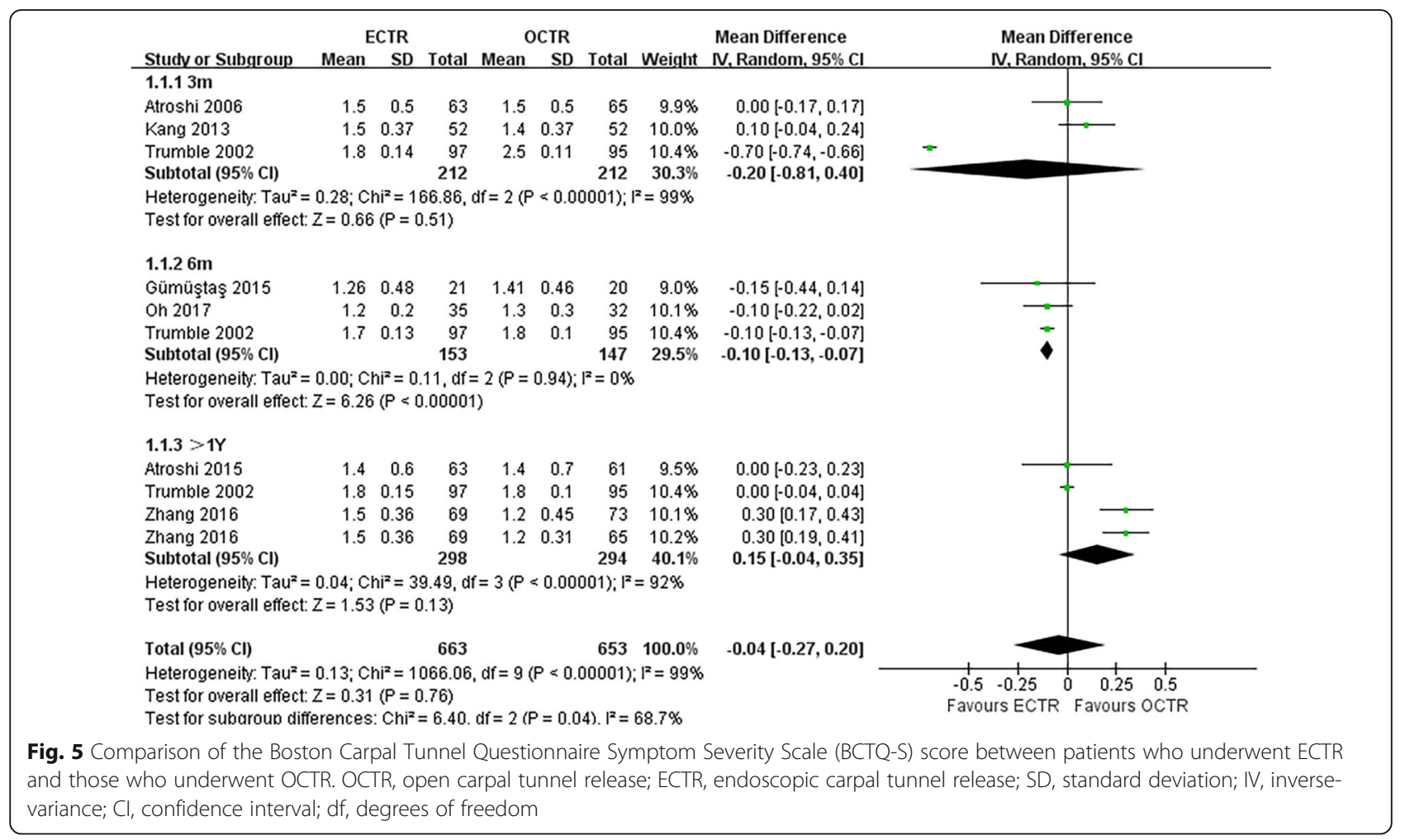

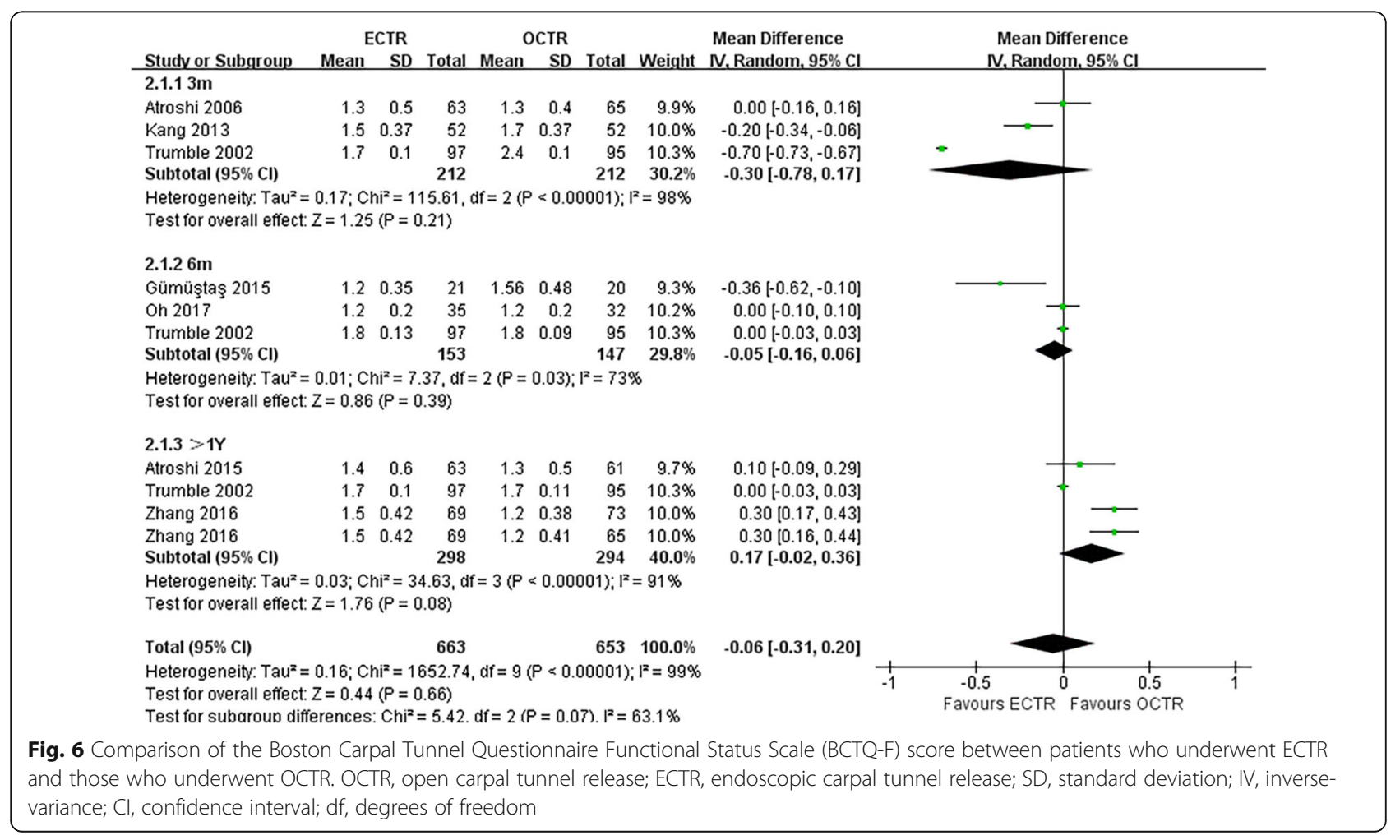




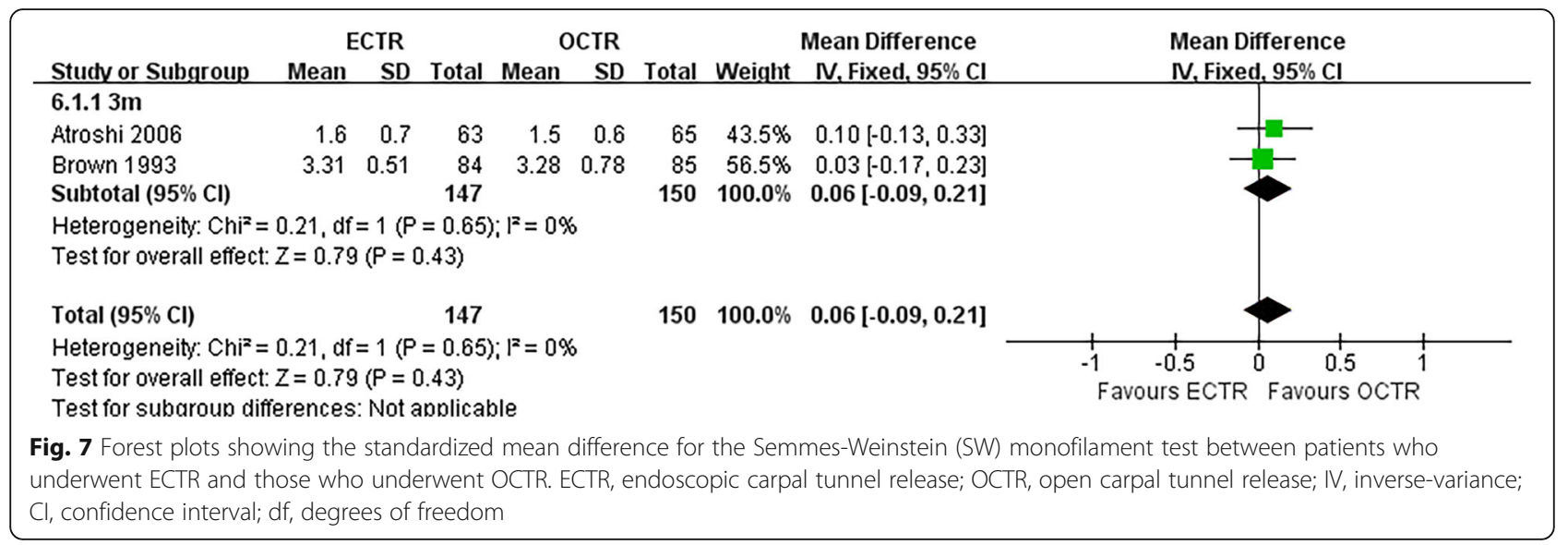

model, $\mathrm{I}^{2}=92 \% ; P<0.00001$; Fig. 5) $[25,51,53]$, and BCTQ-F score at 1 year post-surgery (MD, $0.17 ; 95 \% \mathrm{CI}$, - 0.02 to $0.36 ; P=0.08 ; n=592$; random-effects model, $\mathrm{I}^{2}=91 \% ; P<0.00001$; Fig. 6) $[25,51,53]$ between the ECTR and OCTR groups. Similarly, there were no differences in digital sensation, including the SemmesWeinstein monofilament test score at 3 months postsurgery (MD, $0.06 ; 95 \% \mathrm{CI},-0.09$ to $0.21 ; P=0.43 ; n=$ 297; fixed-effects model, $\mathrm{I}^{2}=0 \% ; P=0.65$; Fig. 7) $[9,31]$ and Two-point Discrimination test score at 1 year post- surgery (MD, $-0.16 ; 95 \% \mathrm{CI},-0.45$ to $0.12 ; P=0.26$; $n=402$; fixed-effects model, $\mathrm{I}^{2}=35 \% ; P=0.20$; Fig. 8) $[50,52,53]$, between the two groups.

\section{Satisfaction rate}

The overall level of satisfaction with the outcome was based on a scale of 0 to 100 points. Two articles provided comparative data on the satisfaction rate $[31,53]$. A portion of the data from Zhang et al. [53] reported a satisfaction rate of up to $90 \%$, with high heterogeneity;

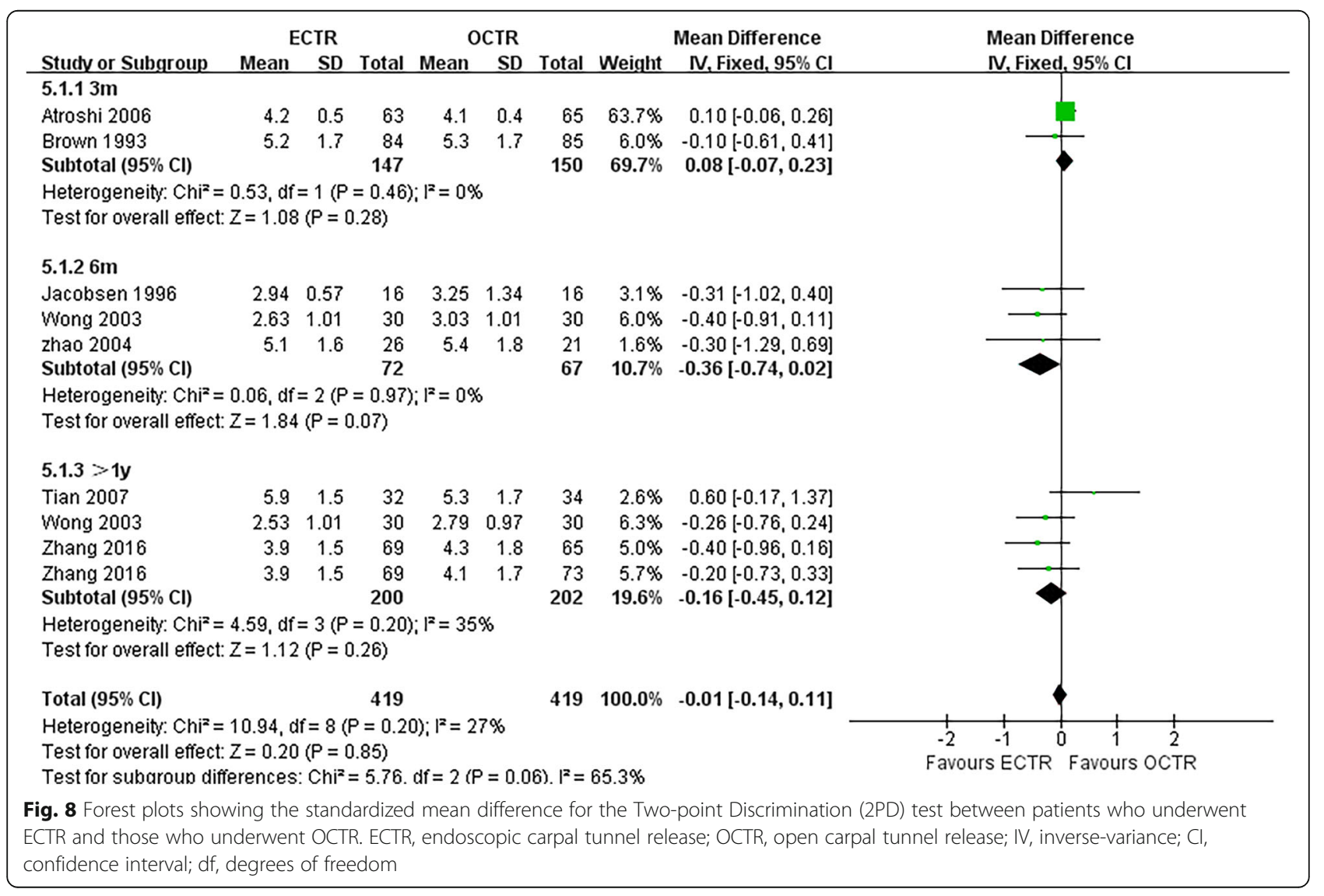




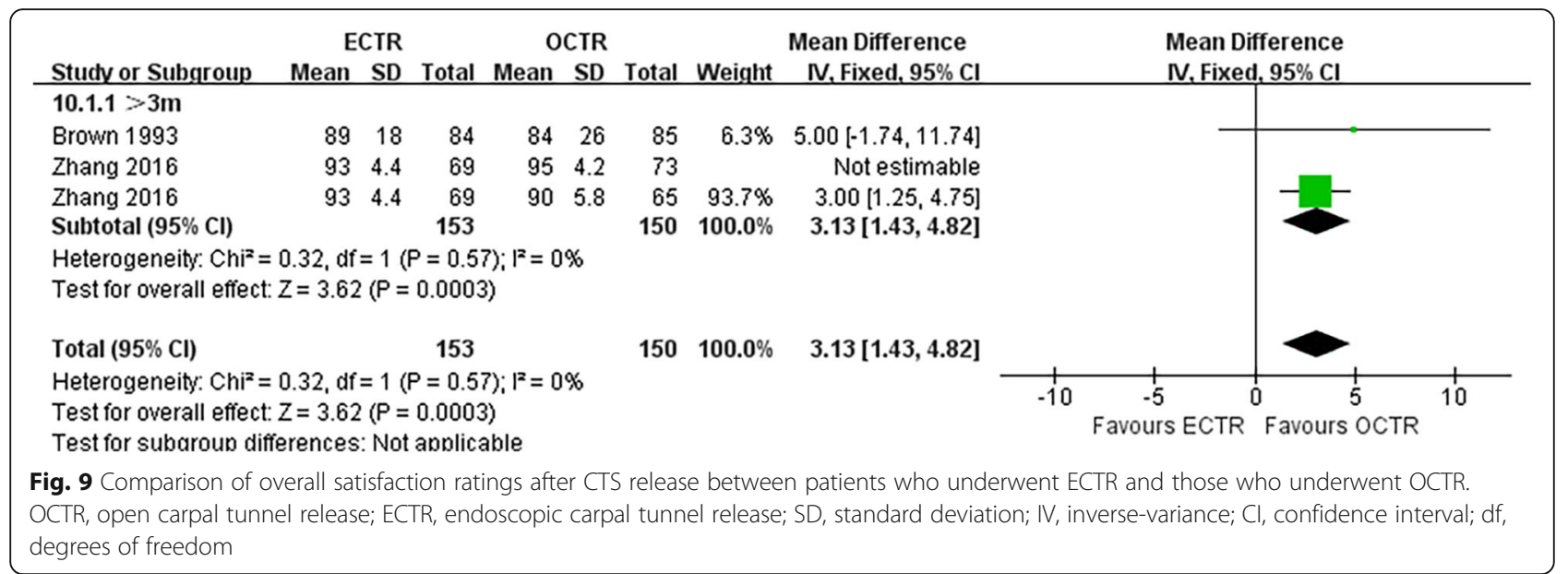

therefore, some of the satisfaction data from that study were eliminated from the present meta-analysis. The pooled data of the two articles showed that the satisfaction rate was significantly higher in the ECTR group than that in the OCTR group (MD, 3.13; 95\% CI, 1.43 to 4.82; $\left.P=0.0003 ; n=303 ; \mathrm{I}^{2}=0 \% ; P=0.57\right)[31,53]$, and the clinical heterogeneity $\mathrm{I}^{2}$ was null (Fig. 9).

\section{Key pinch strength}

The pooled data showed that the key pinch strength of patients who were treated with ECTR was significantly greater than the key pinch strength of patients who were treated with OCTR at 3-months post-surgery (MD, 0.79 kg; $95 \% \mathrm{CI}, 0.27$ to $1.32 ; P=0.003 ; n=297$; fixed-effects model, $\left.\mathrm{I}^{2}=0 \% ; P=0.70\right)[9,31]$ (Fig. 10).

\section{RTW}

Four studies [30, 38, 48, 54] evaluated the time needed to return to work for patients who underwent CTS. The pooled data showed that the RTW times were significantly faster in patients in the ECTR group than those in the OCTR group (MD, -7.25 days; $95 \% \mathrm{CI},-14.31$ to 0.19; $P=0.04 ; n=357$; random-effects model, $\mathrm{I}^{2}=98 \%$;
$P<0.00001$ ) (Fig. 11); however, divergences between studies resulted in large between-study heterogeneity.

\section{Complications}

Twenty-five studies $[9,24,28,30-36,38-40,42,43,45-$ 54 included complete complication rate data and were included in the pooled analysis of overall complications. There were no significant differences between all complications rates $(\mathrm{OR}, 1.06 ; 95 \% \mathrm{CI}, 0.69$ to $1.64 ; P=0.78$; $n=2320$; fixed-effects model, $\mathrm{I}^{2}=16 \% ; P=0.27$ ) (Fig. 12). The rates of transient nerve injury were higher in patients who underwent ECTR than those in patients who underwent OCTR (OR, 4.87; 95\% CI, 1.37 to $17.25 ; P=$ $0.01 ; n=2320$; fixed-effects model, $\mathrm{I}^{2}=0 \% ; P=0.98$ ) (Fig. 13); however, the studies provided evidence that the presence of permanent nerve injury was not significantly different between the two groups (OR, 1.93; 95\% CI, 0.58 to $6.40 ; P=0.28 ; n=2320$; fixed-effects model, $\mathrm{I}^{2}=29 \% ; P=0.24$ ) (Fig. 14). The rates of scar-related complications (scar hypertrophy, scar hyperesthesia, scar pain) were lower in patients who underwent ECTR than those in patients who underwent OCTR (OR, 0.20; 95\% CI, 0.07 to $0.59 ; P=0.004 ; n=2320$; fixed-effects model,

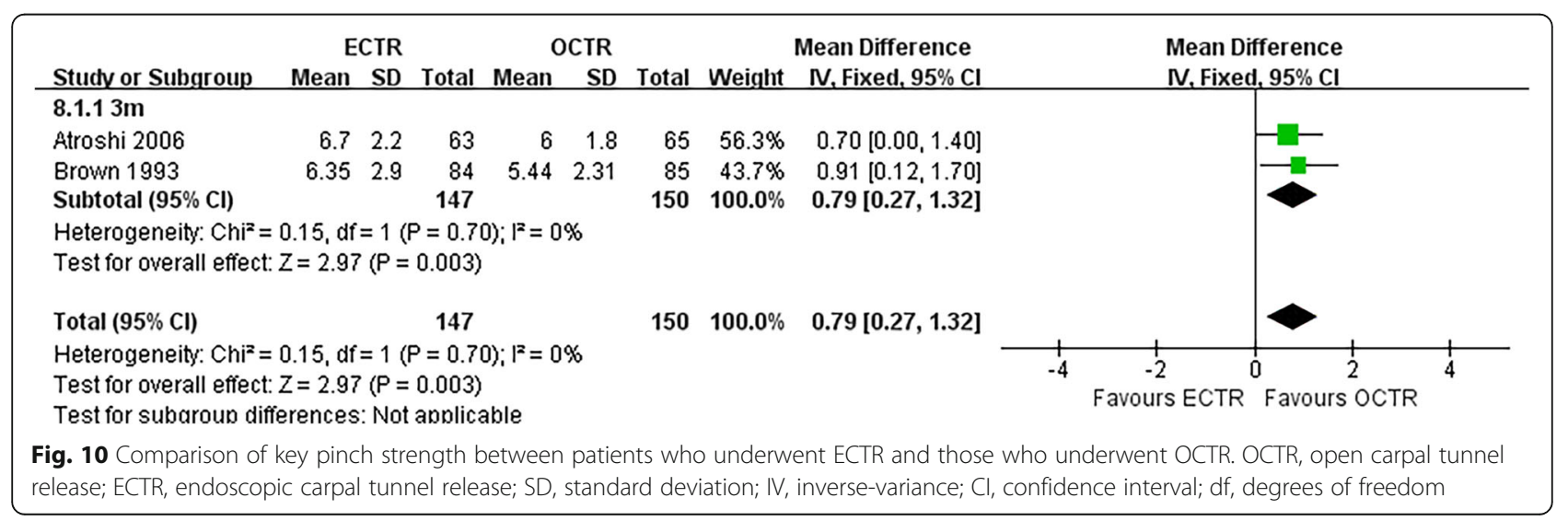




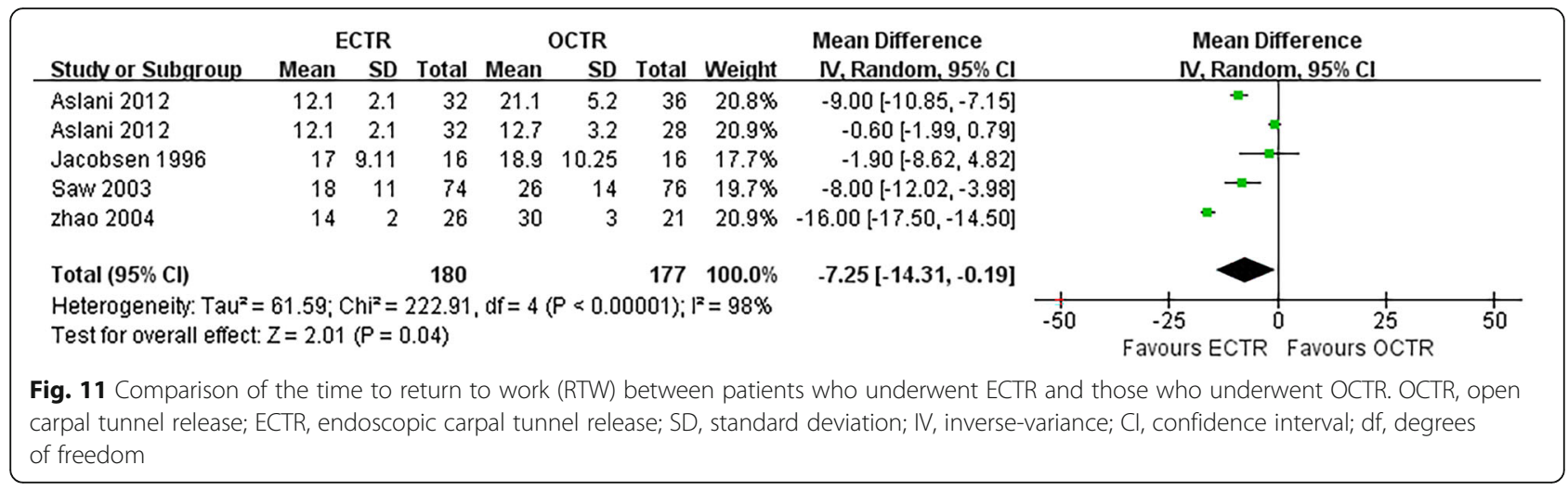

$\mathrm{I}^{2}=0 \% ; P=0.90$ ) (Fig. 15). Other complications, such as hematoma, wound infection, superficial palmar arch injury, persistent symptoms, pillar pain, reflex sympathetic dystrophy, and tendon injury, different were not significantly between the two groups. All outcome variables are summed up and displayed in Table 2.

\section{Publication bias}

Publication bias was assessed by the funnel plot method and Egger's test. The funnel plot shape and Egger's test $(P=0.869)$ appeared essentially symmetric (Fig. 16), indicating no overt publication bias in the analysis of complications.

\section{Discussion}

Since the development of ECTR by Chow (12) and Okutsu et al. [13] in 1989, there has been controversy regarding the superiority of ECTR over OCTR. Accordingly, many original articles have been published on this issue; moreover, several meta-analyses have compared ECTR with OCTR as treatment options for CTS [14, 15, 21-23, 55-57]. However, previous meta-analyses included fewer studies than ours, did not classify the data into subgroups according to different follow-up times, featured only a few assessments of patient outcome, and included central tendency data but not standard deviation. Therefore, we accomplished a large sample-size

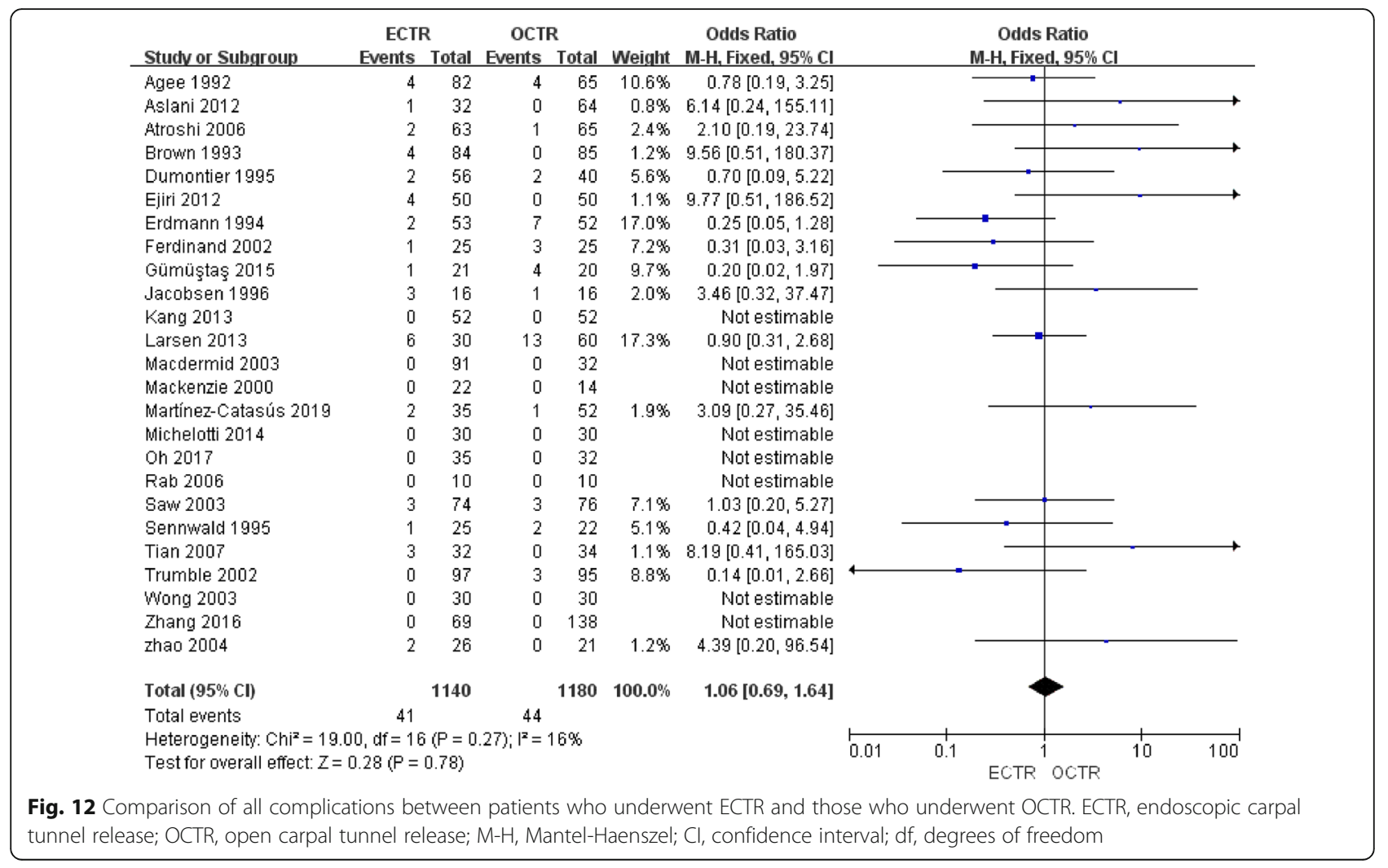




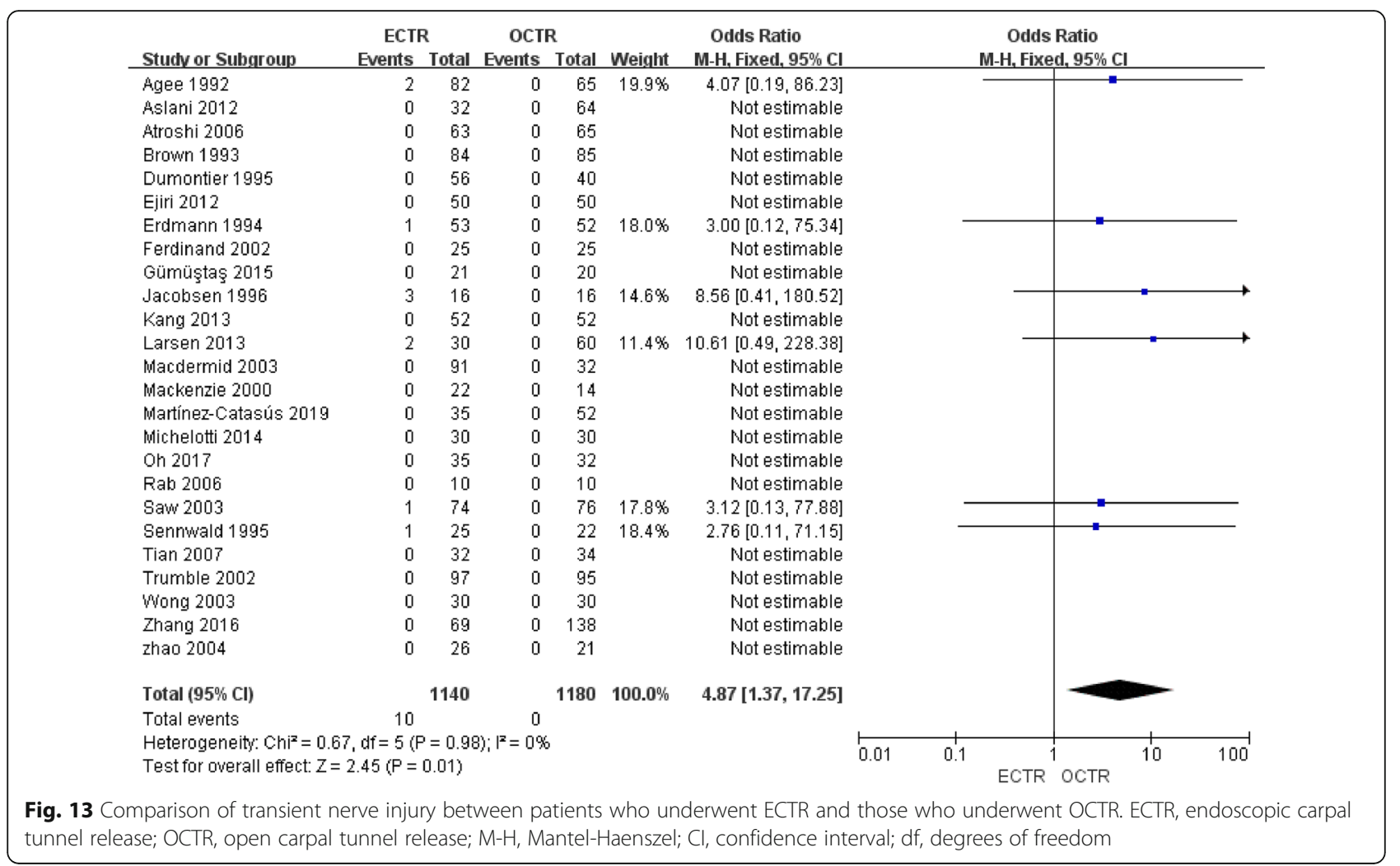

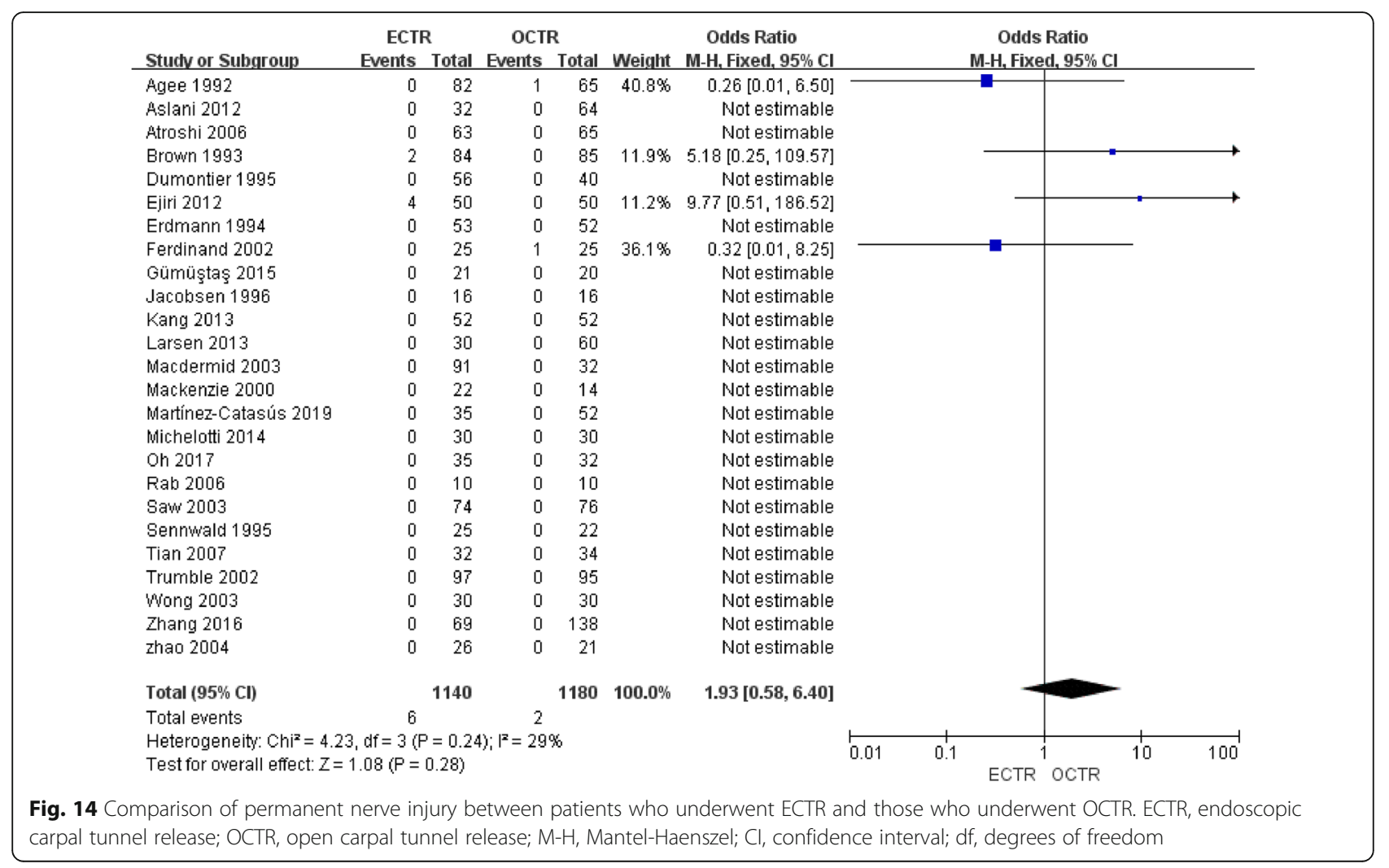




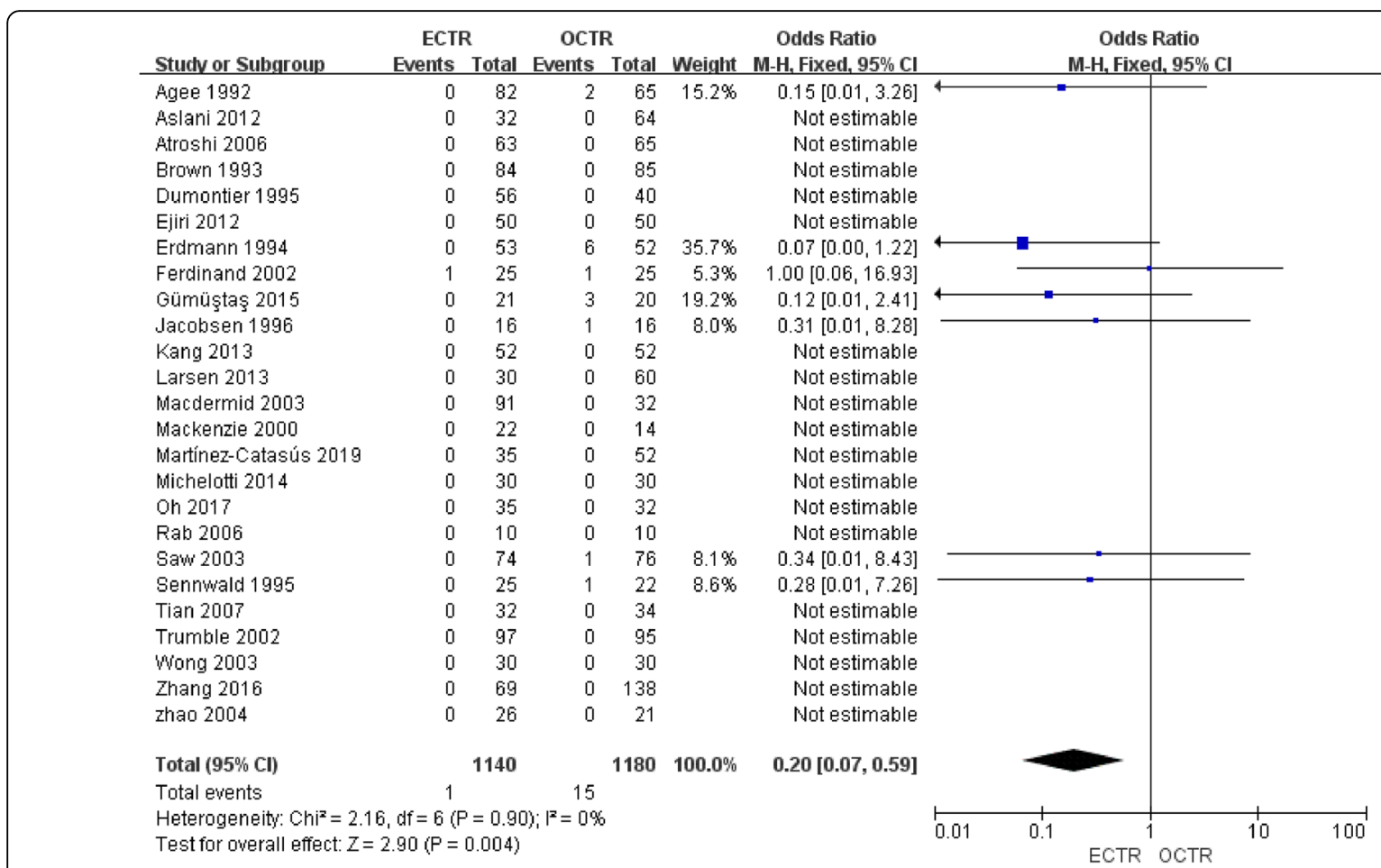

Fig. 15 Comparison of scar-related complications between patients who underwent ECTR and those who underwent OCTR. ECTR, endoscopic carpal tunnel release; OCTR, open carpal tunnel release; $\mathrm{M}-\mathrm{H}$, Mantel-Haenszel; $\mathrm{Cl}$, confidence interval; df, degrees of freedom

meta-analysis of published articles to compare the safety and effectiveness between OCTR and ECTR. The publication bias in this meta-analysis was also minimal, as demonstrated by the results of the funnel plot analysis and Egger's test.

Our meta-analysis reviewed 28 RCTs that consisted of 2320 idiopathic CTS hands treated with two different approaches the OCTR or the ECTR. In the results it can be clearly indicated that there were no significant between-group differences in the operative time, grip strength, BCTQ-S score, BCTQ-F score, digital sensation scores, and the presence of permanent nerve injury. However, the ECTR group exhibited several clinically important advantages over the OCTR group, including higher patient satisfaction rates, greater key pinch strengths, earlier RTW times, and fewer scar-related complications.

Consistent with the present results, previous studies demonstrated that the satisfaction rates of patients in the ECTR group were higher than those of patients in the OCTR group [24, 44, 45]. Compared with the standard open approach, generally small incisions decrease scar tenderness, reduced scarring, mild wound-related complications [53], and improvements in the major functional outcomes (key pinch strength, activities of daily living, and RTW) [31] after endoscopic release is plausible. However, it should be noted that when assessing the patient satisfaction rates, a portion of the data published by Zhang et al. [53] exhibited high heterogeneity. Therefore, these data were excluded from the present meta-analysis. The high heterogeneity was mainly because of the fact that the data compared mini-incisions with endoscopic incisions. Miniincisions are not directly comparable to the standard incisions in OCTR, as they yield a better appearance and tend to have fewer wound-related complications than standard incisions [58].

Herein, the key pinch strength of patients was significantly greater in the ECTR group than that in the OCTR group at 3 months postoperatively $[9,31]$. Additionally, previous studies reported that OCTR was associated with considerable morbidity, including increased and prolonged scar tenderness [11]. Furthermore, other studies revealed that patients who underwent ECTR experienced fewer limitations in their ability to perform daily life activities than did patients who underwent an open technique [30, 59-61]. Michelotti et al. [44] reported early differences in grip and pinch strength after ECTR; however, data were lost as the follow-up duration increased. Further studies should include a more uniform follow-up duration, and additional controlled studies with longer follow-up durations are required to clarify the effects of each technique on activities of daily living.

The finding of our meta-analysis of RCTs suggest that compared to patients treated with OCTR, those who 
Table 2 Summary estimates of outcome variables in the current study

\begin{tabular}{|c|c|c|c|c|c|c|}
\hline Outcome & $\begin{array}{l}\text { No. of } \\
\text { studies }\end{array}$ & $\begin{array}{l}\text { Heterogeneity } \\
\mathrm{p}^{2 \mathrm{a}}(\%)\end{array}$ & $\begin{array}{l}\text { Pooled odds } \\
\text { ratio }^{\text {b }}\end{array}$ & $\begin{array}{l}\text { Mean } \\
\text { difference }^{c}\end{array}$ & $\begin{array}{l}95 \% \text { confidence interval } \\
\text { (lower bound) }\end{array}$ & $\begin{array}{l}\text { 95\% confidence interval } \\
\text { (upper bound) }\end{array}$ \\
\hline Operative time & 4 & 99 & NA & -5.81 & -17.85 & 6.23 \\
\hline Grip strength & 2 & 0 & NA & 1.99 & -0.43 & 4.42 \\
\hline BCTQ-S score & 3 & 92 & NA & 0.15 & -0.04 & 0.35 \\
\hline BCTQ-F score & 3 & 91 & NA & 0.17 & -0.02 & 0.36 \\
\hline $\begin{array}{l}\text { SW monofilament test } \\
\text { score }\end{array}$ & 2 & 0 & NA & 0.06 & -0.09 & 0.21 \\
\hline 2PD test score & 3 & 35 & NA & -0.16 & -0.45 & 0.12 \\
\hline Satisfaction rate & 2 & 0 & NA & 3.13 & 1.43 & 4.82 \\
\hline Key pinch strength & 2 & 0 & NA & 0.79 & 0.27 & 1.32 \\
\hline Return to work & 4 & 98 & NA & -7.25 & -14.31 & -0.19 \\
\hline Complications & 25 & 16 & 1.06 & NA & 0.69 & 1.64 \\
\hline Transient nerve injury & 25 & 0 & 4.87 & NA & 1.37 & 17.25 \\
\hline $\begin{array}{l}\text { Permanent nerve } \\
\text { injury }\end{array}$ & 25 & 29 & 1.93 & NA & 0.58 & 6.4 \\
\hline $\begin{array}{l}\text { Scar-related } \\
\text { complications }\end{array}$ & 25 & 0 & 0.2 & NA & 0.07 & 0.59 \\
\hline Hematoma & 25 & 0 & 1.60 & NA & 0.36 & 7.16 \\
\hline Wound infection & 25 & 0 & 0.53 & NA & 0.15 & 1.97 \\
\hline $\begin{array}{l}\text { Superficial palmar arch } \\
\text { injury }\end{array}$ & 25 & NA & 3.07 & NA & 0.12 & 76.48 \\
\hline Persistent symptoms & 25 & 0 & 2.17 & NA & 0.85 & 5.55 \\
\hline Pillar pain & 25 & 35 & 0.95 & NA & 0.32 & 2.82 \\
\hline $\begin{array}{l}\text { Reflex sympathetic } \\
\text { dystrophy }\end{array}$ & 25 & 0 & 0.40 & NA & 0.10 & 1.65 \\
\hline Tendon injury & 25 & NA & 0.26 & NA & 0.01 & 6.50 \\
\hline
\end{tabular}

$2 P D$ Two-point Discrimination, $B C T Q-F$ Boston Carpal Tunnel Questionnaire Functional Status Scale, $B C T Q-S$ Boston Carpal Tunnel Questionnaire Symptom Severity Scale, ECTR endoscopic carpal tunnel release, NA not applicable, OCTR open carpal tunnel release, SW Semmes-Weinstein

${ }^{a}$ Heterogeneity test: $I^{2}>50 \%$, random-effects analysis model; $I^{2}<50 \%$, fixed-effects analysis model

If odds ratio $>1$, favors ECTR; if odds ratio $<1$, favors OCTR

If mean difference $>0$, favors ECTR; if mean difference $<0$, favors OCTR

treated with ECTR returned to work or daily activities earlier. Consistent with our results, Vasiliadis et al. [22] and Paryavi et al. [56] reported that patients who underwent ECTR experienced less surgical trauma than those who underwent an open technique, and this resulted in less time off work, faster recovery, and better performance of daily activities. However, regarding the RTW data, we noticed that divergences between the studies had large heterogeneity. A possible explanation for this large heterogeneity is that the work flexibility and the nature of the work and daily activities may have been different to a great extend in the included studies. Furthermore, while Sanati et al. [57] demonstrated the minimally invasive techniques have a great superiority over conventional open release in terms of recovery time, they highlighted the remarkable variability in how RTW as an outcome measure was examined across studies. Nevertheless, the effects of such inconsistencies were rather small when only RCTs were considered, similar to that observed in our study. Patients undergoing endoscopic release can return to work and their daily activities sooner when compared with open release.

Our meta-analysis revealed that lower scar-related complication rates and better healing were achieved in the ECTR group while compared to the OCTR group. This may be because of the long palmar incision made during OCTR that may prolong the immobilization time and augment postoperative pain and the risk for hypertrophic or hypersensitive scar formation [22]. In contrast, ECTR uses a small incision and divides the transverse carpal ligament from below, thereby preserving the overlying skin and muscle and resulting in fewer minor complications $[62,63]$, particularly those related to cutaneous scars. However, previous studies demonstrated that ECTR is associated with more nerve injury; therefore, the technique is less favorable owing to its higher risk of the cutaneous branch of the median nerve iatrogenic injury $[15,19,53]$. Contrary to expectations, 


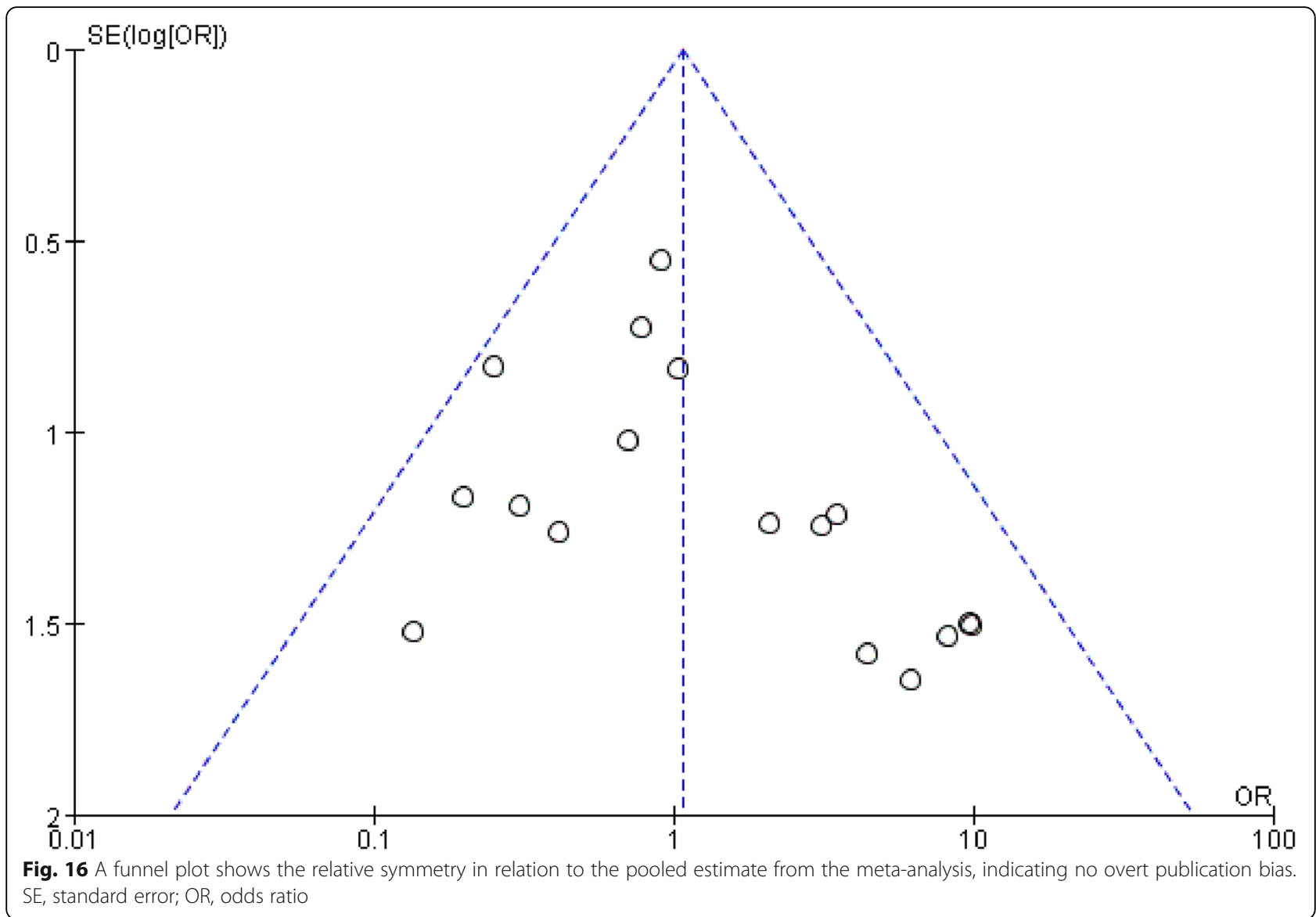

our study did not find a significant difference in the occurrence of permanent nerve injury between the two surgical approaches; furthermore, most noted nerve injuries were transient, and patients still achieved full recovery after surgery [29, 38, 48, 49]. Moreover, Martin et al. [64] developed a novel endoscopic system which may avoid the transient nerve injury occurring with other ECTR methods.

\section{Limitations}

This research had two limitations. Firstly, subgroup analyses of the various ECTR techniques (one-portal and two-portal techniques) and OCTR techniques (mini-incision and long incision) were not performed. Use of different techniques may be associated with different outcomes, however, restricted by the rather limited studies and available data we were unable to divide the patients into subgroup to perform analyses. Secondly, though we included only RCTs, methodological flaws still exist, including unblinded assessments of outcomes.

Nevertheless, our study is novel since it includes the largest number of RCTs to compare ECTR and OCTR techniques. Furthermore, this is the first study to group results into different follow-up times and assess different patient outcomes, thus making the data more comparable. This study is also the first to demonstrate that ECTR is associated with better patient outcomes; we found that after careful manipulation during endoscopic surgery, ECTR can substitute OCTR.

\section{Conclusions}

The present meta-analysis determined that ECTR was superior to OCTR in terms of higher satisfaction rates, improved key pinch strengths, earlier RTW times, and fewer scar-related complications. Our findings suggest that patients with CTS can be effectively managed with ECTR; however, the possibility of transient nerve injury should be considered.

\section{Abbreviations}

CTS: Carpal tunnel syndrome; OCTR: Open carpal tunnel release; ECTR: Endoscopic carpal tunnel release; RCT: Randomized controlled trial; PRISMA: Preferred Reporting Items for Systematic Reviews and MetaAnalyses; BCTQ-S: Boston Carpal Tunnel Questionnaire Symptom Severity Scale; BCTQ-F: Boston Carpal Tunnel Questionnaire Functional Status Scale; RTW: Return to work; GRADE: Grading of Recommendations Assessment, Development, and Evaluation; MD: Mean difference; Cl: Confidence interval; OR: Odds ratio; SE: Standard error

Acknowledgments

Not applicable. 


\section{Author's contributions}

$Y L$ analyzed and interpreted the data and was a major contributor in writing the manuscript. LW collected the data. GW analyzed and interpreted the data. SC revised the article critically. XG designed the study and supervised the study. ZZ designed the study and revised the article critically. All authors read and approved the final manuscript.

\section{Funding}

This work was supported by the Jilin Scientific and Technological Development Program [grant number $20190905003 S F]$. The funding institution was responsible for the provision of literature database resources and literature purchase. The funding body had no role in the design of the study, the collection, analysis, and interpretation of data, or the writing of the manuscript.

\section{Availability of data and materials}

The datasets used and/or analyzed during the current study are available from the corresponding author on reasonable request.

\section{Ethics approval and consent to participate}

This article does not contain any studies involving human participants conducted by any of the authors.

\section{Consent for publication}

Not applicable.

\section{Competing interests}

The authors declare that they have no competing interests.

\section{Author details}

'Department of Hand Surgery, China-Japan Union Hospital of Jilin University, No. 126 Xiantai Street, Changchun, Jilin 130033, P.R. China. ${ }^{2}$ Department of Orthopedics, China-Japan Union Hospital of Jilin University, No. 126 Xiantai Street, Changchun, Jilin 130033, P.R. China.

Received: 29 January 2020 Accepted: 21 April 2020

Published online: 27 April 2020

\section{References}

1. Devana SK, Jensen AR, Yamaguchi KT, D'Oro A, Buser Z, Wang JC, et al. Trends and complications in open versus endoscopic carpal tunnel release in private payer and medicare patient populations. Hand (N Y). 2019;14:45561. https://doi.org/10.1177/1558944717751196.

2. Atroshi I, Gummesson C, Johnsson R, Ornstein E, Ranstam J, Rosén I. Prevalence of carpal tunnel syndrome in a general population. JAMA. 1999; 282:153-8. https://doi.org/10.1001/jama.282.2.153.

3. Bongers FJ, Schellevis FG, van den Bosch WJ, van der Zee J. Carpal tunnel syndrome in general practice (1987 and 2001): incidence and the role of occupational and non-occupational factors. Br J Gen Pract. 2007;57:36-9.

4. Burton $\mathrm{CL}$, Chen $Y$, Chesterton $L S$, Van der Windt DA. Trends in the prevalence, incidence, and surgical management of carpal tunnel syndrome between 1993 and 2013: an observational analysis of UK primary care records. BMJ Open. 2018;8:e020166. https:/doi.org/10.1136/bmjopen-2017020166.

5. Middleton SD, Anakwe RE. Carpal tunnel syndrome. BMJ. 2014;349:g6437. https://doi.org/10.1136/bmj.g6437.

6. Gerritsen AA, de Vet HC, Scholten RJ, Bertelsmann FW, de Krom MC, Bouter LM. Splinting vs surgery in the treatment of carpal tunnel syndrome: a randomized controlled trial. JAMA. 2002;288:1245-51. https://doi.org/10. 1001/jama.288.10.1245.

7. Chesterton LS, Blagojevic-Bucknall M, Burton C, Dziedzic KS, Davenport G, Jowett SM, et al. The clinical and cost-effectiveness of corticosteroid injection versus night splints for carpal tunnel syndrome (INSTINCTS trial): an open-label, parallel group, randomised controlled trial. Lancet. 2018;392: 1423-33. https://doi.org/10.1016/S0140-6736(18)31572-1.

8. Ebenbichler GR, Resch KL, Nicolakis P, Wiesinger GF, Uhl F, Ghanem AH, et al. Ultrasound treatment for treating the carpal tunnel syndrome: randomised "sham" controlled trial. BMJ. 1998;316:731-5. https://doi.org/10. 1136/bmj.316.7133.731.

9. Atroshi I, Larsson GU, Ornstein E, Hofer M, Johnsson R, Ranstam J. Outcomes of endoscopic surgery compared with open surgery for carpal tunnel syndrome among employed patients: randomised controlled trial. BMJ. 2006;332:1473. https://doi.org/10.1136/bmj.38863.632789.1F.

10. Phalen GS. The carpal-tunnel syndrome, seventeen years' experience in diagnosis and treatment of six hundred fifty-four hands. J Bone Joint Surg Am. 1966;48:211-28.

11. Boya H, Özcan Ö, Özteki NHH. Long-term complications of open carpal tunnel release. Muscle Nerve. 2008;38:1443-6. https://doi.org/10.1002/mus. 21068.

12. Chow JC. Endoscopic release of the carpal ligament: a new technique for carpal tunnel syndrome. Arthroscopy. 1989;5:19-24. https://doi.org/10.1016/ 0749-8063(89)90085-6.

13. Okutsu I, Ninomiya S, Takatori Y, Ugawa Y. Endoscopic management of carpal tunnel syndrome. Arthroscopy. 1989;5:11-8. https://doi.org/10.1016/ 0749-8063(89)90084-4

14. Chen L, Duan X, Huang X, LV J, Peng K, Xiang Z. Effectiveness and safety of endoscopic versus open carpal tunnel decompression. Arch Orthop Trauma Surg. 2014;134:585-93. https://doi.org/10.1007/s00402-013-1898-z.

15. Sayegh ET, Strauch RJ. Open versus endoscopic carpal tunnel release: a meta-analysis of randomized controlled trials. Clin Orthop Relat Res. 2015; 473:1120-32. https://doi.org/10.1007/s11999-014-3835-z.

16. Cobb TK, Knudson GA, Cooney WP. The use of topographical landmarks to improve the outcome of Agee endoscopic carpal tunnel release. Arthroscopy. 1995;11:165-72. https://doi.org/10.1016/0749-8063(95)90062-4.

17. Concannon MJ, Brownfield ML, Puckett CL. The incidence of recurrence after endoscopic carpal tunnel release. Plast Reconstr Surg. 2000;105:1662-5. https://doi.org/10.1097/00006534-200004050-00010.

18. Makowiec RL, Nagle DJ, Chow JC. Outcome of first-time endoscopic carpal tunnel release in a teaching environment. Arthroscopy. 2002;18:27-31. https://doi.org/10.1053/jars.2002.29903.

19. Murphy RX Jr, Jennings JF, Wukich DK. Major neurovascular complications of endoscopic carpal tunnel release. J Hand Surg [Am]. 1994;19:114-8. https://doi.org/10.1016/0363-5023(94)90233-X.

20. Chung KC, Walters MR, Greenfield ML, Chernew M. Endoscopic versus open carpal tunnel release: a cost-effectiveness analysis. Plast Reconstr Surg. 1998; 102:1089-99. https://doi.org/10.1097/00006534-199809040-00026.

21. Zuo D, Zhou Z, Wang H, Liao Y, Zheng L, Hua Y, et al. Endoscopic versus open carpal tunnel release for idiopathic carpal tunnel syndrome: a metaanalysis of randomized controlled trials. J Orthop Surg Res. 2015;10:12. https://doi.org/10.1186/s13018-014-0148-6.

22. Vasiliadis HS, Nikolakopoulou A, Shrier I, Lunn MP, Brassington R, Scholten $\mathrm{RJ}$, et al. Endoscopic and open release similarly safe for the treatment of carpal tunnel syndrome. A systematic review and meta-analysis. PLoS One. 2015;10:e0143683. https://doi.org/10.1371/journal.pone.0143683.

23. Hu K, Zhang T, Xu W. Intraindividual comparison between open and endoscopic release in bilateral carpal tunnel syndrome: a meta-analysis of randomized controlled trials. Brain Behav. 2016;6:e00439. https://doi.org/10. 1002/brb3.439.

24. Martínez-Catasús A, Lobo-Escolar L, García-Bonet J, Corrales-Rodríguez M, Pasarín-Martínez A, Berlanga-de-Mingo D. Comparison between single portal endoscopic, 1-cm open carpal tunnel release. Hand Surg Rehabil. 2019;38:202-6. https://doi.org/10.1016/j.hansur.2019.02.003.

25. Atroshi I, Hofer M, Larsson GU, Ranstam J. Extended follow-up of a randomized clinical trial of open vs endoscopic release surgery for carpal tunnel syndrome. JAMA. 2015;314:1399-401. https://doi.org/10.1001/jama.2015.12208.

26. Moher D, Liberati A, Tetzlaff J, Altman DG, PRISMA group. Preferred reporting items for systematic reviews and meta-analyses: the PRISMA statement Ann Intern Med 2009;151:264-269. doi:https://doi.org/10.7326/ 0003-4819-151-4-200908180-00135.

27. Guyatt GH, Oxman AD, Schünemann HJ, Tugwell P, Knottnerus A. GRADE guidelines: a new series of articles in the journal of clinical epidemiology. J Clin Epidemiol. 2011;64:380-2. https://doi.org/10.1016/j.jclinepi.2010.09.011.

28. Agee JM, McCarroll HR Jr, Tortosa RD, Berry DA, Szabo RM, Peimer CA. Endoscopic release of the carpal tunnel: a randomized prospective multicenter study. J Hand Surg [Am]. 1992;17:987-95. https://doi.org/10. 1016/s0363-5023(09)91044-9.

29. Atroshi I, Hofer M, Larsson GU, Ornstein E, Johnsson R, Ranstam J. Open compared with 2-portal endoscopic carpal tunnel release: a 5-year followup of a randomized controlled trial. J Hand Surg [Am]. 2009;34:266-72. https://doi.org/10.1016/j.jhsa.2008.10.026.

30. Aslani HR, Alizadeh K, Eajazi A, Karimi A, Karimi MH, Zaferani Z, et al, Comparison of carpal tunnel release with three different techniques. Clin 
Neurol Neurosurg. 2012;114:965-8. https://doi.org/10.1016/j.clineuro.2012.02. 017.

31. Brown RA, Gelberman RH, Seiler JG 3rd, Abrahamsson SO, Weiland AJ, Urbaniak JR, et al. Carpal tunnel release. A prospective, randomized assessment of open and endoscopic methods. J Bone Joint Surg Am. 1993; 75:1265-75. https://doi.org/10.2106/00004623-199309000-00002.

32. Dumontier C, Sokolow C, Leclerq C, Chauvin P. Early results of conventional versus two-portal endoscopic carpal tunnel release. A prospective study. J Hand Surg (Br). 1995;20:658-62. https://doi.org/10.1016/s02667681(05)80130-5.

33. Ejiri S, Kikuchi S, Maruya M, Sekiguchi Y, Kawakami R, Konno S. Short-term results of endoscopic (Okutsu method) versus palmar incision open carpal tunnel release: a prospective randomized controlled trial. Fukushima J Med Sci. 2012;58:49-59. https://doi.org/10.5387/fms.58.49.

34. Erdmann MW. Endoscopic carpal tunnel decompression. J Hand Surg (Br). 1994;19:5-13. https://doi.org/10.1016/0266-7681(94)90038-8.

35. Ferdinand RD, MsacLean JG. Endoscopic versus open carpal tunnel release in bilateral carpal tunnel syndrome. A prospective, randomised, blinded assessment. J Bone Joint Surg (Br). 2002;84:375-9. https://doi.org/10.1302/ 0301-620X.84B3.12224.

36. Gümüștas SA, Ekmekçi B, Tosun HB, Orak MM, Bekler Hi. Similar effectiveness of the open versus endoscopic technique for carpal tunnel syndrome: a prospective randomized trial. Eur J Orthop Surg Traumatol. 2015;25:1253-60 https://doi.org/10.1007/s00590-015-1696-0.

37. Taleisnik J. The palmar cutaneous branch of the median nerve and the approach to the carpal tunnel. J Bone Joint Surg Am. 1973;55:1212-7.

38. Jacobsen MB, Rahme H. A prospective, randomized study with an independent observer comparing open carpal tunnel release with endoscopic carpal tunnel release. J Hand Surg (Br). 1996;21:202-4. https:// doi.org/10.1016/s0266-7681(96)80097-0.

39. Kang HJ, Koh IH, Lee TJ, Choi YR. Endoscopic carpal tunnel release is preferred over mini-open despite similar outcome: a randomized trial. Clin Orthop Relat Res. 2013;471:1548-54. https://doi.org/10.1007/s11999-012-2666-z.

40. Larsen MB, Sørensen Al, Crone KL, Weis T, Boeckstyns ME. Carpal tunnel release: a randomized comparison of three surgical methods. J Hand Surg Eur Vol. 2013;38:646-50. https://doi.org/10.1177/1753193412475247.

41. Menon J. Endoscopic carpal tunnel release: a single-portal technique. Contemp Orthop. 1993;26:109-16.

42. Macdermid JC, Richards RS, Roth JH, Ross DC, King GJ. Endoscopic versus open carpal tunnel release: a randomized trial. J Hand Surg [Am]. 2003;28: 475-80. https://doi.org/10.1053/jhsu.2003.50080.

43. Mackenzie DJ, Hainer R, Wheatley MJ. Early recovery after endoscopic vs. short-incision open carpal tunnel release. Ann Plast Surg. 2000;44:601-4. https://doi.org/10.1097/00000637-200044060-00004.

44. Michelotti B, Romanowsky D, Hauck RM. Prospective, randomized evaluation of endoscopic versus open carpal tunnel release in bilateral carpal tunnel syndrome: an interim analysis. Ann Plast Surg. 2014;73(Suppl 2):S157-60. https://doi.org/10.1097/SAP.0000000000000203.

45. Michelotti BM, Vakharia KT, Romanowsky D, Hauck RM. A prospective, randomized trial comparing open and endoscopic carpal tunnel release within the same patient. Hand (N Y). 2018;21:1558944718812129. https://doi. org/10.1177/1558944718812129.

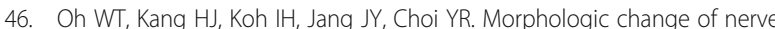
and symptom relief are similar after mini-incision and endoscopic carpal tunnel release: a randomized trial. BMC Musculoskelet Disord. 2017;18:65. https://doi.org/10.1186/s12891-017-1438-z.

47. Rab M, Grünbeck M, Beck H, Haslik W, Schrögendorfer KF, Schiefer HP, et al. Intra-individual comparison between open and 2-portal endoscopic release in clinically matched bilateral carpal syndrome. J Plast Reconstr Aesthet Surg. 2006;59:730-6. https://doi.org/10.1016/j.bjps.2005.11.018.

48. Saw NL, Jones S, Shepstone L, Meyer M, Chapman PG, Logan AM. Early outcome and cost-effectiveness of endoscopic versus open carpal tunnel release: a randomized prospective trial. J Hand Surg (Br). 2003;28:444-9. https://doi.org/10.1016/s0266-7681(03)00097-4.

49. Sennwald GR, Benedetti R. The value of one-portal endoscopic carpal tunnel release: a prospective randomized study. Knee Surg Sports Traumatol Arthrosc. 1995;3:113-6. https://doi.org/10.1007/BF01552386.

50. Tian $\mathrm{Y}$, Zhao H, Wang T. Prospective comparison of endoscopic and open surgical methods for carpal tunnel syndrome. Chin Med Sci J. 2007;22:104-7.

51. Trumble TE, Diao E, Abrams RA, Gilbert-Anderson MM. Single-portal endoscopic carpal tunnel release compared with open release: a prospective, randomized trial. J Bone Joint Surg Am. 2002;84:1107-15. https://doi.org/10.2106/00004623-200207000-00003.

52. Wong KC, Hung LK, Ho PC, Wong JM. Carpal tunnel release. A prospective, randomised study of endoscopic versus limited-open methods. J Bone Joint Surg (Br). 2003;85:863-8. https://doi.org/10.1302/0301-620X.85B6.13759.

53. Zhang $X$, Huang $X$, Wang $X$, Wen $S$, Sun J, Shao X. A randomized comparison of double small, standard, and endoscopic approaches for carpal tunnel release. Plast Reconstr Surg. 2016;138:641-7. https://doi.org/10. 1097/PRS.0000000000002511.

54. Zhao H, Zhao Y, Tian Y, Yang B, Qiu GX. Comparison of endoscopic versus open surgical treatment of carpal tunnel syndrome. Zhongguo Yi Xue Ke Xue Yuan Xue Bao. 2004;26:657-60.

55. Thoma A, Veltri K, Haines T, Duku E. A meta-analysis of randomized controlled trials comparing endoscopic and open carpal tunnel decompression. Plast Reconstr Surg. 2004;114:1137-46. https://doi.org/10. 1097/01.prs.0000135850.37523.d0

56. Paryavi E, Zimmerman RM, Means KR Jr. Endoscopic compared with open operative treatment of carpal tunnel syndrome. JBJS Rev. 2016;4. https://doi. org/10.2106/JBJS.RWW.15.00071.

57. Sanati KA, Mansouri M, Macdonald D, Ghafghazi S, Macdonald E, Yadegarfar G. Surgical techniques and return to work following carpal tunnel release: a systematic review and meta-analysis. J Occup Rehabil. 2011;21:474-81. https://doi.org/10.1007/s10926-011-9310-8.

58. Li G, Kong L, Kou N, Wang Y, Yu K, Bai J, et al. Tian, The comparison of limited-incision versus standard-incision in treatment of carpal tunnel syndrome: a meta-analysis of randomized controlled trials. Medicine (Baltimore). 2019;98:e15372. https://doi.org/10.1097/MD.0000000000015372.

59. Gellman H, Kan D, Gee V, Kuschner SH, Botte MJ. Analysis of pinch and grip strength after carpal tunnel release. J Hand Surg [Am]. 1989;14:863-4. https://doi.org/10.1016/50363-5023(89)80091-7.

60. Cotton P. Symptoms may return after carpal tunnel surgery. JAMA. 1991; 265:1922-5. https://doi.org/10.1001/jama.265.15.1922b.

61. Macfarlane D, Williams TG. Efficacy of provocative tests for diagnosis of carpal tunnel syndrome. Lancet. 1990;335:727. https://doi.org/10.1016/01406736(90)90843-t.

62. Kim PT, Lee HJ, Kim TG, Jeon IH. Jeon, current approaches for carpal tunnel syndrome. Clin Orthop Surg. 2014;6:253-7. https://doi.org/10.4055/cios.2014. 6.3.253.

63. Padua L, Coraci D, Erra C, Pazzaglia C, Paolasso I, Loreti C, et al. Carpal tunnel syndrome: clinical features, diagnosis, and management. Lancet Neurol. 2016;15:1273-84. https://doi.org/10.1016/S1474-4422(16)30231-9.

64. Martin KD, Dützmann S, Sobottka SB, Rambow S, Mellerowicz HA, Pinzer T, et al. Retractor-endoscopic nerve decompression in carpal and cubital tunnel syndromes: outcomes in a small series. World Neurosurg. 2014;82: e361-70. https://doi.org/10.1016/j.wneu.2013.09.026.

\section{Publisher's Note}

Springer Nature remains neutral with regard to jurisdictional claims in published maps and institutional affiliations.
Ready to submit your research? Choose BMC and benefit from:
- fast, convenient online submission
- thorough peer review by experienced researchers in your field
- rapid publication on acceptance
- support for research data, including large and complex data types
- gold Open Access which fosters wider collaboration and increased citations
- maximum visibility for your research: over $100 \mathrm{M}$ website views per year
At BMC, research is always in progress.
Learn more biomedcentral.com/submissions 